\title{
Remote Pit Operation Enhancement System: Concept Selection Method and Evaluation Criteria
}
S. A. Bailey
J. T. Smalley
J. M. Alzheimer
J. C. Tucker
C. P. Baker
P. L. Valdez

December 1999

Prepared for the U.S. Department of Energy under Contract DE-AC06-76RLO 1830 


\title{
DISCLAIMER
}

This report was prepared as an account of work sponsored by an agency of the United States Government. Neither the United States Government nor any agency thereof, nor Battelle Memorial Institute, nor any of their employees, makes any warranty, express or implied, or assumes any legal liability or responsibility for the accuracy, completeness, or usefulness of any information, apparatus, product, or process disclosed, or represents that its use would not infringe privately owned rights. Reference herein to any specific commercial product, process, or service by trade name, trademark, manufacturer, or otherwise does not necessarily constitute or imply its endorsement, recommendation, or favoring by the United States Government or any agency thereof, or Battelle Memorial Institute. The views and opinions of authors expressed herein do not necessarily state or reflect those of the United States Government or any agency thereof.

\author{
PACIFIC NORTHWEST NATIONAL LABORATORY \\ operated by \\ BATTELLE \\ for the \\ UNITED STATES DEPARTMENT OF ENERGY \\ under Contract DE-AC06-76RLO 1830
}

\author{
Printed in the United States of America \\ Available to DOE and DOE contractors from the \\ Office of Scientific and Technical Information, P.O. Box 62, Oak Ridge, TN 37831; \\ prices available from (615) 576-8401. \\ Available to the public from the National Technical Information Service, \\ U.S. Department of Commerce, 5285 Port Royal Rd., Springfield, VA 22161
}

This document was printed on recycled paper. 


\section{Remote Pit Operation Enhancement System: Concept Selection Method and Evaluation Criteria}
S. A. Bailey
J. T. Smalley
J. M. Alzheimer
J. C. Tucker
C. P. Baker
P. L. Valdez

December 1999

Prepared for

the U.S. Department of Energy

under Contract DE-AC06-76RLO 1830

This work is funded by the Office of Science and Technology, within the Department of Energy's Office of Environmental Management, under the Robotics Crosscut Program.

Pacific Northwest National Laboratory

Richland, Washington 99352 


\section{Summary}

The purpose of this report is to document the concept selection and evaluation process used in FY 1999 by the Robotics Crosscut Program for a proposed Remote Pit Operations System for the Hanford Site.

The Pacific Northwest National Laboratory (PNNL) was tasked with developing a set of concept designs for performing difficult, time consuming, and expensive tasks in the Hanford Tank Farm equipment pits. Based on commercially available equipment, the system concepts were required to have the ability to functionally complete six pit operations tasks: jumper handling, size reduction, debris removal, decontamination/fixative application, tool handling, and jumper positioning. Key user desires included the selection of simple systems and the complete turnover of the remote system to Tank Farm Operations after cold testing and operator training.

After reviewing current practice activities and the technical requirements developed by Numatec Hanford, the project performed a literature search of historical data/trade studies, and assessed similar activities at other Department of Energy sites.

Six classes of potential solutions were developed: gantry robot, manipulator, and jib crane; telescoping boom with manipulator; stationary frame with long-reach manipulator; in-pit mobile platform with manipulator; crane-mounted platform with manipulator(s); and manipulator on stationary platform inside of the pit.

These classes of solutions were then broken down into base components-13 platforms and 12 manipulators. These components were evaluated against 10 first cut criteria, and three platforms and four manipulators were eliminated from consideration.

After the first cut evaluation, and assessment of tooling requirements, 15 remote pit operations systems were generated based on appropriate platform and manipulator configurations. Each of the 15 systems were graded as to its ability to perform the six pit operations tasks, and further evaluated based on initial capital cost, length of schedule to reach cold testing, and required auxiliary equipment. The results of this second cut evaluation yielded nine concepts, which were grouped together into five final potential concepts.

The five final potential concepts included: gantry-based systems with a 3-degree-of-freedom (DOF) wrist or 6-DOF manipulator; grade-level gantry with a 6-DOF manipulator; YZ gantry with 6-DOF manipulator; telescoping boom, out of pit, with a 3-DOF wrist or 6-DOF manipulator; and a cranemounted platform with a 6-DOF manipulator. The balance of system was also evaluated, including operator interface, cameras and video equipment, control architecture, and sensors.

In late September 1999, the project team, Tanks Focus Area, and Numatec Hanford staff held a concept selection meeting in which the gantry-based system with a 6-DOF manipulator was chosen as the preferred concept. 


\section{Acknowledgments}

This work was prepared with the support of the following contributors:

Headquarters: $\quad$ Office of Science and Technology

Robotics Crosscut Program

J. DeGregory, Manager

Field Office: $\quad$ Albuquerque Operations Office

Robotics Crosscut Program

L. W. Yarbrough, Manager

Operations Office: Richland Operations Office

Science and Technology Programs Division

C. R. Richins, Technical Program Officer

Contractor: $\quad$ Pacific Northwest National Laboratory

Environmental Management

Environmental Management Science and Technology Office

R. A. Brouns, Manager 


\section{Contents}

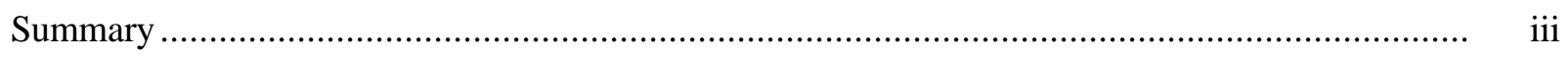

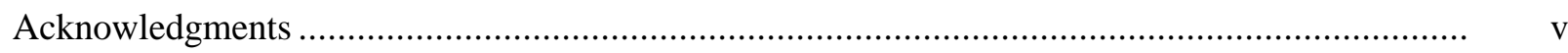

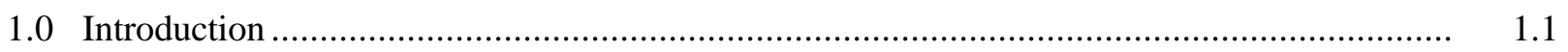

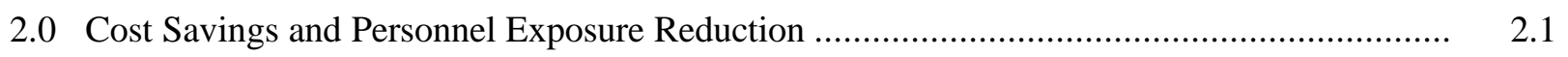

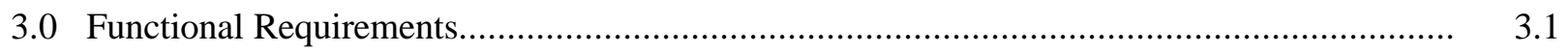

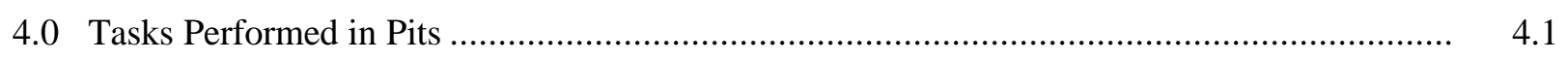

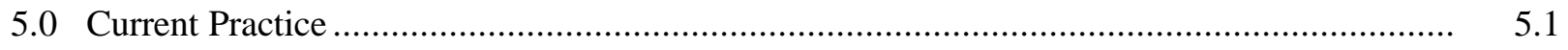

6.0 Historical Data/Trade Studies_Hanford ...........................................................

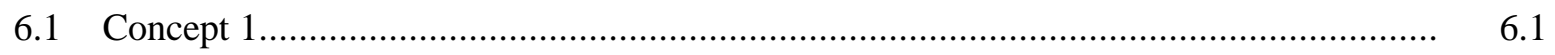

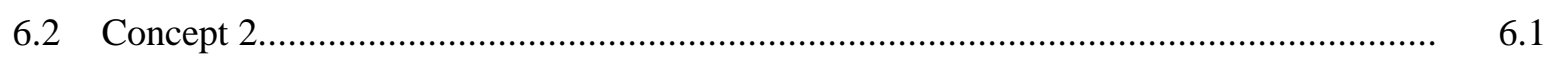

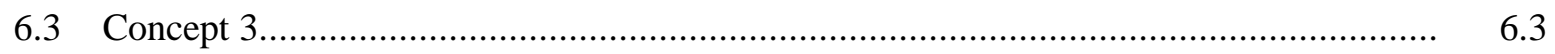

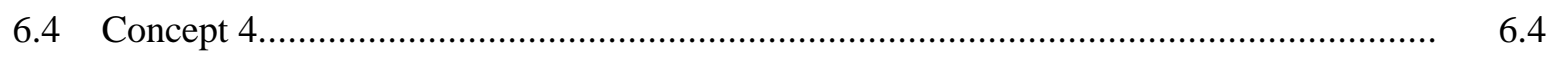

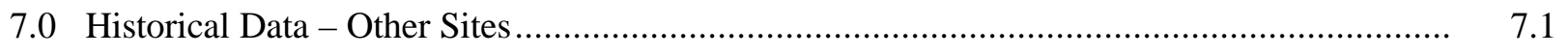

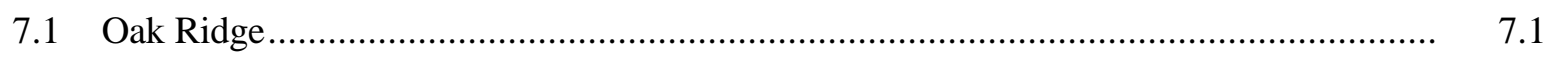

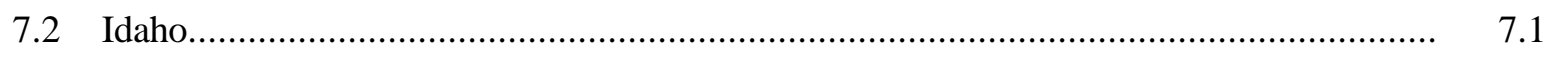

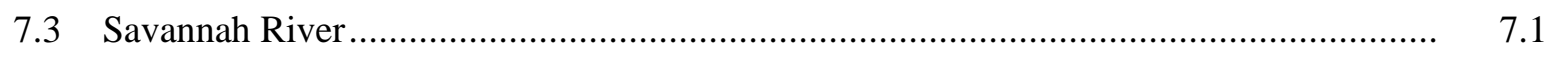

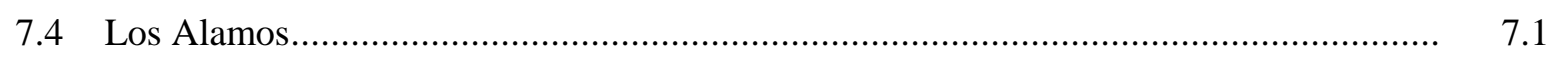

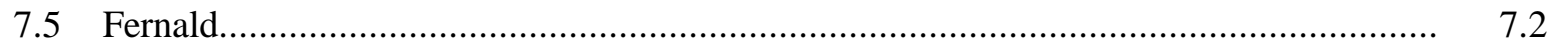

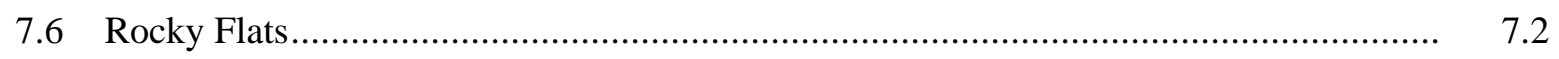

7.7 Similar Remote Applications within the DOE Complex........................................ 7.2

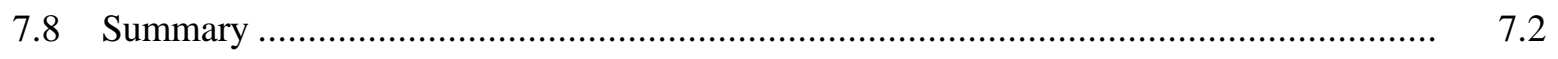


8.0 Classes of Potential Remote Systems Solutions .....................................................

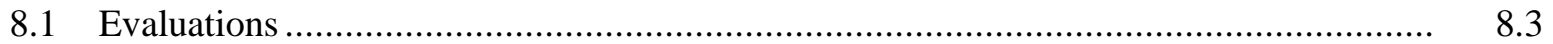

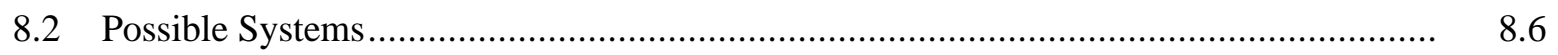

8.3 Second Cut—System Ranking of Task Abilities ..................................................... $\quad 8.10$

8.4 Additional Second Cut Criteria...................................................................... 8.11

9.0 Detailed Discussion on the Final Five Potential Concepts................................................ 9.1

9.1 Gantry-Based Systems with 3-DOF Wrist or 6-DOF Manipulator................................ 9.1

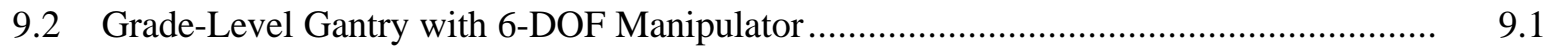

$9.3 \mathrm{Y}, \mathrm{Z}$ Gantry with 6-DOF Manipulator ............................................................... 9.2

9.4 Telescoping Boom with 3-DOF Wrist or 6-DOF Manipulator .................................... 9.3

9.5 Crane-Mounted Platform with 6-DOF Manipulator .................................................. 9.6

10.0 Commercially Available Boom Systems .......................................................... 10.1

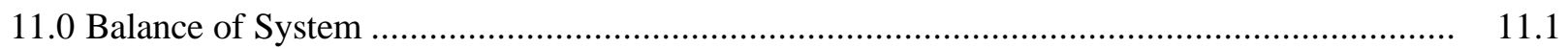

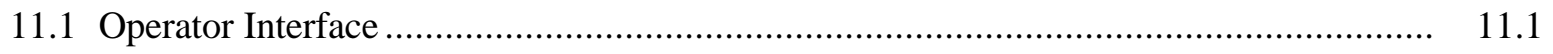

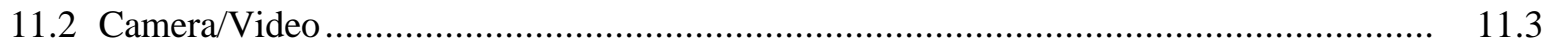

11.3 Controls Architecture/Integration .............................................................. 11.5

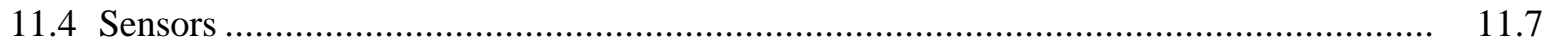

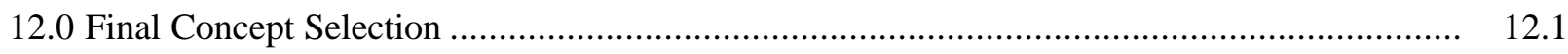

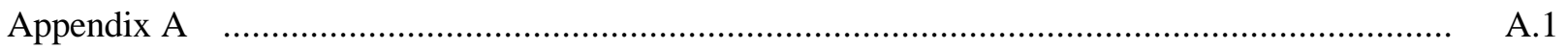




\section{Figures}

6.1 Concept 1: Knuckle Boom Crane and Conan Manipulator .......................................... 6.2

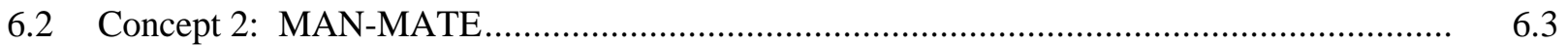

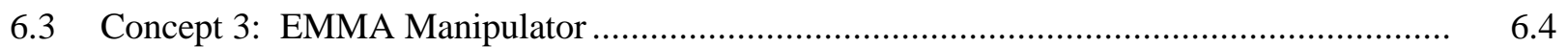

6.4 Concept 4: KT-30 Demolition Machine with Furnace Descaling Machine.......................... 6.5

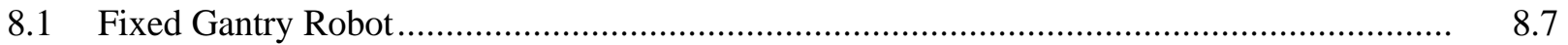

8.2 3-DOF Wrist for Gantry Mast or Manipulator........................................................

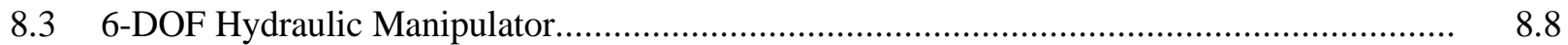

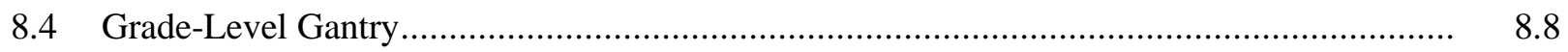

8.5 Mobile Tracked Vehicle with 6-DOF Manipulator........................................................ 8.9

11.1 Dual Joystick Design with Toggle and Selector Switches.......................................... 11.4

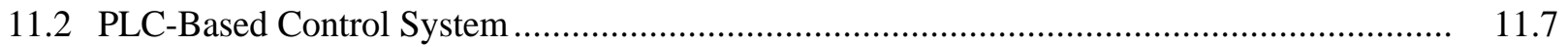

\section{Tables}

A.1 Pit Identification and Dimensional Data .....

A.1

A.2 First and Second Cut Criteria and Rankings .............................................................. A. 


\subsection{Introduction}

Over the past 40 years, more than 600 waste transfer pits have been constructed at the Hanford Site for use in the transfer of liquid high-level waste. During the many years of operation, the pits have become contaminated with radioactive material from leaks and spills. Radiation levels in excess of $40 \mathrm{R} / \mathrm{hr}$ have been measured in some of the pits. The pits have also been used to accumulate worn out components and parts.

There are 15 styles of pits, including pump pits, sluice pits, valve pits, diversion boxes, distribution pits, heel pits, receiving pits, and filter pits. Prior to the transfer of tank waste to the Privatization Contractor, British Nuclear Fuels Limited (BNFL) for processing and disposal, the tank waste must pass through a number of these pits. Many of these pits will have to be modified before the waste can be transferred. Table A.1 in Appendix A gives the ID, location, dimension, and function of the pits that will need to be accessed and modified prior to waste transfer to BNFL. For Phase I of Privatization, 60 pits are involved, and for Phase II, all remaining pits will be used.

The physical dimensions of the pits vary. They are underground reinforced concrete structures equipped with removable concrete cover blocks (usually three per pit) for radiation shielding. Each cover block is approximately 10 -foot by 4 -foot by 1 -foot and they are stepped/keyed. Each block weighs approximately 5000 pounds. Two styles of cover blocks are in use. The tops of the pits are typically 1 to 2 feet above grade. The pits contain items such as pump drive motors, pipe jumpers (for directing waste flow into various nozzles located on the walls of the pits), flow meters, leak detectors, and other process equipment.

Current methods for modifying, operating, cleaning, and decontaminating these pits are labor intensive, costly, and result in a high dose to workers. Currently, work associated with pits is the single largest contribution to River Protection Program (RPP) operations dose levels. For example, the dose in the 241-C-106 pits was $40 \mathrm{R} / \mathrm{hr}$. After investing $\$ 2 \mathrm{M}$ and 5 months, the dose had been reduced to only $20 \mathrm{R} / \mathrm{hr}$. During the pit operations, 25 person-rems were accumulated.

Available documentation for most pits is poor. As an example, most of the radiation maps from the previous entries were boxed up and sent to archives. Because of this, it is a significant task to get the paper work in place for each pit entry, because each is now treated as a first of a kind entry. The range of conditions (radiation and contamination levels) varies significantly from one pit to another. Because of this, a significant uncertainty has to be taken into account during the planning phase for pit work. If the dose measurement performed after the removal of the cover blocks is significantly different from the planned value, delay or down time can be experienced.

Numatec Hanford Corporation (NHC) has the lead to explore the enhanced pit operations for the RPP, and they have teamed with the Tanks Focus Area (TFA) and the Robotics Crosscut Program (RBX) to address remote system needs. Efforts to date by NHC include the identification of three areas where operational costs may be reduced. These are environmental enclosures to reduce weather-driven down time, deployment platforms for remote operations, and end-effectors for performing operations in the pits. 
The process for defining functions and requirements $(\mathrm{F} \& \mathrm{Rs})$ for remote platforms and end-effectors has been initiated and is being led by NHC. The NHC-led pit enhancement team desires participation from the RBX in the F\&R development process, but requests that the bulk of work completed by the RBX be focused on developing concepts for the remote systems and end-effectors.

There is a strong desire to do pit operations better, with better meaning any or all of the following: faster, safer, less dose, less cost, etc. There is a strong desire to benefit from the application of remote technology. 


\subsection{Cost Savings and Personnel Exposure Reduction}

There is little to no hard data that is readily available on the cost savings that could be associated with a remote pit operations system. While it is clear that a decrease in personnel exposure and a decrease in the time required to complete tasks in pits would reduce costs and/or increase productivity, establishing a baseline cost for pit operations is complicated by the way such costs are incurred. It is difficult to associate specific costs to specific tasks.

The basic concept is to remove workers from the pits. An expected outcome might be 50 to $75 \%$ reduction of manpower and exposure. There should be significant improvements in efficiency, translating directly to schedule reductions.

There is justification for remote pit operations from both personnel protection (as low as reasonably achievable [ALARA]), and from a cost-effectiveness perspective. With proper implementation of remote systems, a significant reduction in exposure and operating costs can be expected.

The following engineering estimates were developed in discussions between S. A. Krieg/T. H. May/ D. B. Hagmann (NHC and Cogema) based on the experience in decontaminating and refurbishing the C-106 pump pit for Project W-320.

A remote pit operation system is expected to reduce the time and cost by at least $50 \%$. Based on the $\$ 1.5 \mathrm{M}$ cost for the $\mathrm{C}-106$ pump pit work, this leads to a $\$ 750 \mathrm{~K}$ reduction in cost per pit.

Additionally, it is expected to reduce personnel exposures by $75 \%$. Based on the C-106 pump pit work, this leads to a 19 man-rem reduction in exposure per pit.

Based on the C-106 estimates, the following data is provided on estimated costs to perform specific tasks within pits in accordance with the current baseline:

\begin{tabular}{||l|l|l||}
\hline Task Description & Cost & Task Duration \\
\hline Remove jumpers & $\$ 50 \mathrm{~K}$ & 5 days \\
\hline Remove 125 HP pump & $125 \mathrm{~K}$ & 5 days \\
\hline Decontaminate pit & $400 \mathrm{~K}$ & 20 days \\
\hline Install nuzzle/cure & $50 \mathrm{~K}$ & 30 days \\
\hline Install jumper & $32 \mathrm{~K}$ & 5 days \\
\hline
\end{tabular}

Additional data from Project W-320 (sluicing of the pump pit and sluice pit) includes the following. The project spanned 2.5 years with 5.5 months of actual cleanout. $\$ 1 \mathrm{M}$ was spent, and 34,000 craft hours used for the removal of 1,024 cubic feet of transuranic (TRU) debris. The dose in the pits was reduced from $40 \mathrm{R} / \mathrm{hr}$ to $20 \mathrm{R} / \mathrm{hr}$, and there was a 25 person-rem exposure. Personnel used shielded walls and a greenhouse. 


\subsection{Functional Requirements}

The identification of functions and requirements associated with a remote work platform are under control of the RPP. The following drivers were identified by the RPP:

- Cost reduction

- $\quad$ minimizing required field personnel

- reducing the infrastructure (e.g., crane)

- simplifying field procedures and documentation to the work

- reducing rework (approximately $10 \%$ of the work requires re-entry into the pits)

- Improving safety

- reducing the dose to the workers

- limiting contamination spread

- waste minimization

- Schedule improvement

- $\quad$ tasks that are difficult to perform now (e.g., clogged drain)

- decontamination and dismantlement (D\&D) work

- flexibility for emerging technology

The following specific requirements were identified:

- Turn-key system-The RBX brings in equipment and trains, then complete turnover to operations. Tank Farm Operations sets up, runs, and maintains. The system shall be designed to be maintained by field crews with a minimum of special support equipment.

- It is highly desirable, from the user's perspective, that the equipment be commercially available, and that the system be able to perform multiple tasks.

- All environmental system sensors (non-system related, such as gamma detectors) will be provided by the user.

- Serious desire by the user that the system be SIMPLE, SIMPLE, SIMPLE and not try to have a system that promises to do everything.

- Use of existing equipment (gantries, for example) is desired by the user, if practical.

- Load handling capacity of up to 350 pounds (to pick up a pump motor); lift capacity of 675 pounds (handling of heaviest pipe jumpers), and horizontal rotate capability. 
- It is desirable to avoid imposing a load on the side of the pits (i.e., for mounting or stabilizing equipment) because the project would then have to justify/verify that the load distribution to the pit would not be damaging to the wall.

- Any deployment structure shall be able to be placed inside or outside of fabric green houses, inside or outside of portable hard-shell enclosures, or inside permanent pit enclosures.

- Any system manipulators will be telerobotically controlled.

- Manipulator systems must comply with ANSI/RIA R15.06-1999.

- Skid mounted devices are preferred over truck/tractor. Issues are significant in allowing vehicles of any kind to drive over the tanks or in the tank farms. The following weight and size limits would allow unrestricted road access to all tank farms:

Weight - The maximum tire loading of a transport trailer is $600 \mathrm{lbs} / \mathrm{inch}$ of tire width.

Height - A maximum height limit of 13.5 feet (load on trailer).

Width - A maximum width limit of 11 feet.

Exceeding these limits would impose additional restrictions. Multiple packages (equipment and trailers, etc.) may be used to maintain size and weight below limits as long as setup/takedown time remains as low as practical.

- It is desirable to be non-dependent on tank farm cranes. Cranes are a premium in the tank farms, and it is desirable that they be used only for tasks like removal of cover blocks.

- The system shall perform the pit tasks without increasing the airborne contamination releases to the environment.

- The system will minimize the possibility of the spread of contamination within the pit and especially to the area (ground surfaces) surrounding the pits being serviced.

- The system should be easy to decontaminate. The system shall have an outer covering with as few irregularities as possible to expedite decontamination efforts following use. Self-decontaminate to the extent possible (i.e., if a manipulator and gantry are used, the manipulator would be able to spray down the gantry prior to human entry into the pit).

- Where there is a possibility that removal of surface decontamination may not be adequate, provisions shall be made to allow containment (i.e., wrapping/sleeving in plastic) of the equipment to prevent the equipment from becoming contaminated, and to prevent spread of contamination during handling or transportation. 
- The construction material for all surfaces likely to become contaminated shall be selected to support decontamination without the use of hazardous chemicals.

- Parts exposed to the pit environment (i.e., decon. sprays) must be suitable for use in caustic environment $(\mathrm{NaOH}, \mathrm{pH} \approx 12)$.

- The system shall permit easy accessibility to perform routine maintenance and calibrations. Adjustment, maintenance, repair, calibration and testing should be done to the greatest extent possible with standard tools and test equipment.

- The system shall enable, to the greatest extent possible, hands-on maintenance of the remote subsystems following decontamination.

- It is desirable to have distinct components within the system for ease of removal and replacement. Components should be selected and installed to minimize maintenance efforts.

- All control functions for the system shall be able to be performed from a remote (outside of a radiation zone) control station, and be operated by field crew operators. The control station may be required to be located outside the tank farm fence (approx. 250 feet).

- The system shall have the ability to navigate the entire length/width of the pits. The following summarizes the pit dimensions encompassing the pits. The system tooling does not have to be designed to reach all parts of a pit without moving the support structure.

Length min. $=6$ feet, $\max .=40$ feet

Width $\min .=5$ feet, $\max .=16$ feet

Depth $\min .=3$ feet, $\max .=15$ feet

- The equipment and system shall fall into the General Service Systems safety classification.

- Flammable gas constraints need to be considered for approximately $10 \%$ of the pits.

- Welding of structures and components shall be in accordance with the requirements of ANSI/AWS D1.1, ANSI/AWS D1.2, Section IX of the Boiler and Pressure Vessel Code, or other approved national welding standard.

- Primary load-bearing welds (>200 pounds) of lifting devices and their attachment to structural members, as well as other identified critical welds, shall be magnetic particle tested or penetration tested and visually tested per AWS D1.1 on final pass. Other non-destructive evaluation (NDE) methods may be used. 
- If hydraulic fluid is used, a material safety data sheet (MSDS) must be supplied for pre-approval by Hanford. There are severe restrictions on the type of fluid that can be used, the discharge of organic compounds during operation, and all possible failure modes. Shell Tellus has been found acceptable in recent projects.

- All electrical components shall be designed in accordance with the National Electrical Code (ANSI/NFPA 70). All safety electrical components shall be tested in accordance with IEEE-577.

- The system, including all deployment platforms, sensors, tools, and support equipment shall weigh less than 80,000 pounds (dome loading constraint).

- The base of the crane, if used to deploy the system, must be positioned a minimum of 20 feet from the perimeter of the pit wall so that the crane's weight can be excluded from the total weight limitation.

- The system needs to have the ability to be moved from pit to pit using standard transport trucks/trailers and cranes, as necessary, within a reasonable time frame and with a limited crew (less than one shift for setup).

- The system shall function under the following environmental conditions:

Operating temperature $\quad 10$ to $110^{\circ} \mathrm{F}$

Storage temperature $\quad-20$ to $120^{\circ} \mathrm{F}$

Design wind speed $\quad 80 \mathrm{mph}$

Operating wind speed $25 \mathrm{mph}$

Humidity $\quad 0$ to $100 \%$

Elevation $\quad 0$ t0 600 feet above sea level

- Exposed equipment shall withstand sand, dust, rain, snow, wind and direct sunlight.

- The system assemblies shall be capable of receiving power from both a portable power supply (i.e., diesel generator) for normal operation, and from individual Tank Farm site-power for recovery of selected loads from off-normal events.

- System shall provide for remote recovery following subsystem component failure.

- Clearances from pit walls to surrounding obstacles vary, and particular attention shall be paid to minimizing any support structure interference with these obstacles.

- A useful life of 10 years shall be the minimum acceptable. Component replacement may be necessary during this time but shall be minimized to the extent possible. 


\subsection{Tasks Performed in Pits}

To target the function of the remote pit operations system, NHC has identified six high priority (high return on investment) pit operations tasks four medium, and two low priority tasks. These are

$\underline{\text { Task Description }}$

1. New jumper installation

2. Removing old jumpers

3. Repair/replacement of jumper connectors (upset condition)

4. Size reduction (old jumpers, pipes, flanges, etc.)

5. Decon of walls and floors

6. Positioning torque wrench for PUREX connector tightening or loosening. Tightening and loosening PUREX connector nuts and other fasteners.

7. Applying fixative and/or paint to walls and floors

8. Debris removal, including washing down dispersible and debris to pit drains (i.e., wet and dry sludge and dirt from floors)

9. Cleaning walls and floors of old fixative and/or paint

10. Pit plug removal and installation in floor pipes accessing the tanks

11. Radiation mapping of pits

12. Position lifting hook for heavy lifting
Priority

High

High

High

High

High

High

Medium

Medium

Medium

Medium

Low

Low

In terms of manipulator and tool functions, these tasks can be combined into six categories of capabilities: jumper handling, size reduction, debris removal, decontamination/fixative (spray only), tool holding (including brush and roller), and jumper positioning.

Jumper handling is lifting and moving into place a typical jumper used in pits. A jumper is a 4-inch diameter, 12-foot long pipe. The system needs two capabilities: 1) the capacity to lift the jumper weight, and 2) enough dexterity and precision to properly align the jumper with the end fittings. It is assumed that the gripper will be used to grasp the jumper.

Size reduction is cutting up jumpers and angles using gripper-held tools such as band saws, shears, or rotary wheel cutters. The system needs the capacity to manipulate the cutting tools with a moderate level dexterity and precision.

Debris removal is picking up relatively large pieces such as cut up jumper sections and using tools such as scrapers or shovels to collect smaller pieces and place them in a bucket.

Decontamination/fixative application requires holding and pointing a low or high-pressure spray nozzle. 
Tool holding includes all tasks not otherwise considered where a tool would be held in the gripper.

Jumper positioning is aligning a crane-supported jumper, or other device. 


\subsection{Current Practice}

Information presented in this section primarily came from Tank Farm equipment operators. Baseline activities include the following: remote viewing by mirrors, hand signals and radios; use of ropes and poles to guide tools being deployed by the crane; and personnel work behind shield blankets.

Most pit work is currently done with an initial water wash decontamination followed by spraying or fogging a fixative. These tasks can generally be done with the cover blocks in place by using the existing 3 -inch-diameter valve actuator penetrations. The most general task is replacing or moving jumpers.

For pits that are very high in dose rate, T-handled tools are suspended from the crane and manipulated with a pair of ropes. Some tools on poles are also used. The operators like these tools and think that they are adequate for most tasks. However, some tasks are hard to do with poles and the crane. There are five or six seriously contaminated pits on site that need special consideration. Each of these may need to be opened once in several years.

Using T-handle tools and poles is very dose-intensive work that can prevent workers from being available to work at other pits because of accumulated dose limits.

The following lists the baseline technology for the six activities:

1. Jumper handling Baseline is crane-deployed tools

2. Size reduction

4-inch schedule 40 pipe

Baseline is band saw suspended from crane 4-inch flex tubing

6-inch channel

Baseline is "jaws of life" suspended from crane

Baseline is band saw suspended from crane

3. Debris removal

Baseline is T-handled tools and crane

4. Decontamination/fixative application

Baseline is T-handled tools and crane

5. Tool handling

T-handled tools, poles, crane

6. Jumper positioning

Crane-deployed tools 


\subsection{Historical Data/Trade Studies-Hanford}

Staff reviewed project documentation from previous pit-related programs that dealt with improving remote operations. This includes Project W-467 and the following information from C-106.

Five conceptual designs were developed by private vendors, under contract to Lockheed Martin Hanford Corporation's C-106 Project, for a system to clean out, enhance, and refurbish the tank farms waste transfer pits. The following is a short description of four of these concepts. The fifth concept is restricted in use (proprietary) and cannot be disclosed. HNF-3979, Rev. 0 "Description of Waste Transfer Pit Enhancement Systems" documents all of the concepts.

\subsection{Concept 1}

The system is based on a Palfinger knuckle boom crane used as a coarse positioner and a Conan manipulator used as a fine positioner for working tools (Figure 6.1). The knuckle boom crane is skid mounted and can be transported to the pit work site by truck or crane. The crane has a maximum horizontal extension of 37 feet, 9 inches and 20 feet of vertical reach. Lift capacity ranges from $8400 \mathrm{lb}$ at 8 feet from the base to 1650 pounds at full horizontal extension. The small cross section extension tubes are well suited for booting with a flexible, collapsible molded bellows for improved deconability.

A Conan fine manipulator is mounted on the end of the knuckle boom crane and is a six degree-offreedom (DOF) hydraulic manipulator with a lift capacity of $375 \mathrm{lb}$ at its full reach of 67 inches. The Conan is rate controlled (like a backhoe) and has no electronic control system. This offers a low cost, simple to operate system.

This system can be used with the current vinyl confinement enclosures, although a rigid panel confinement enclosure is recommended. The modular enclosure consists of a series of prefabricated, interchangeable modules that can be assembled into enclosures (including roofs) of many sizes. The modules are reusable, easy to decontaminate, allow operation in windy conditions, and eliminate the waste created by the vinyl greenhouse.

Multiple cameras are provided to assist in viewing the operations and a complete set of replaceable tools is identified to perform the required pit operations.

\subsection{Concept 2}

This concept is based on the MAN-MATE line of industrial manipulators used in hostile environments (Figure 6.2). The MAN-MATE manipulator is a master slave, force-feedback manipulator with task specific end-effectors and other tooling to accomplish the pit enhancement task. The manipulator can be crawler mounted, forklift mounted, or overhead gantry mounted. 


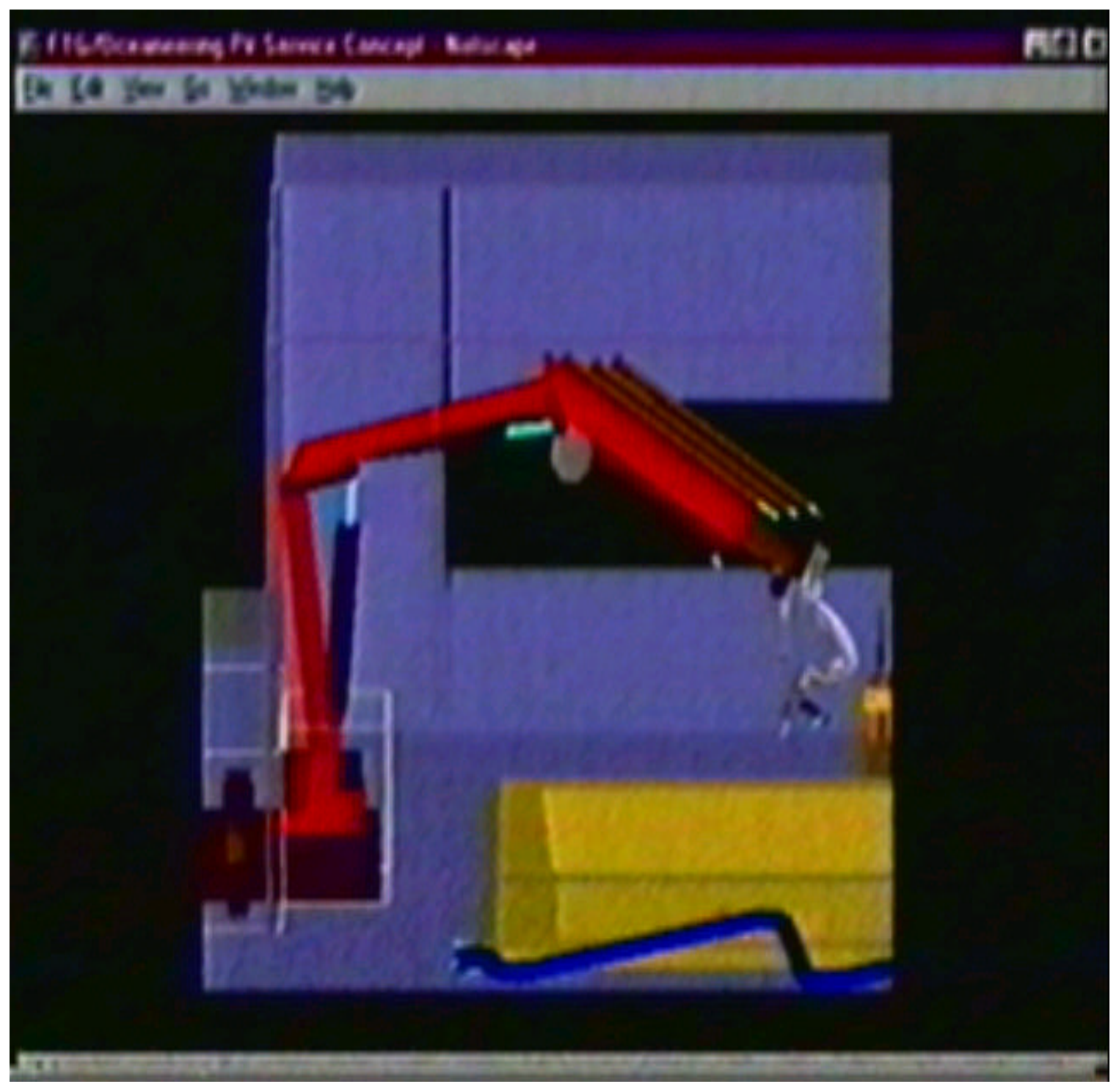

Figure 6.1. Concept 1: Knuckle Boom Crane and Conan Manipulator

The proposed MAN-MATE 1600 industrial manipulator has a load capacity of $1500 \mathrm{lb}$. at full extension and reach up to 19 feet (26 feet with extension). The MAN-MATE can be mounted on a skid, tracked vehicle or wheeled vehicle.

This system is designed around a proven device that has been in successful operation for a number of years. The system uses a standard array of replaceable end-effectors and a vinyl enclosure tent. 


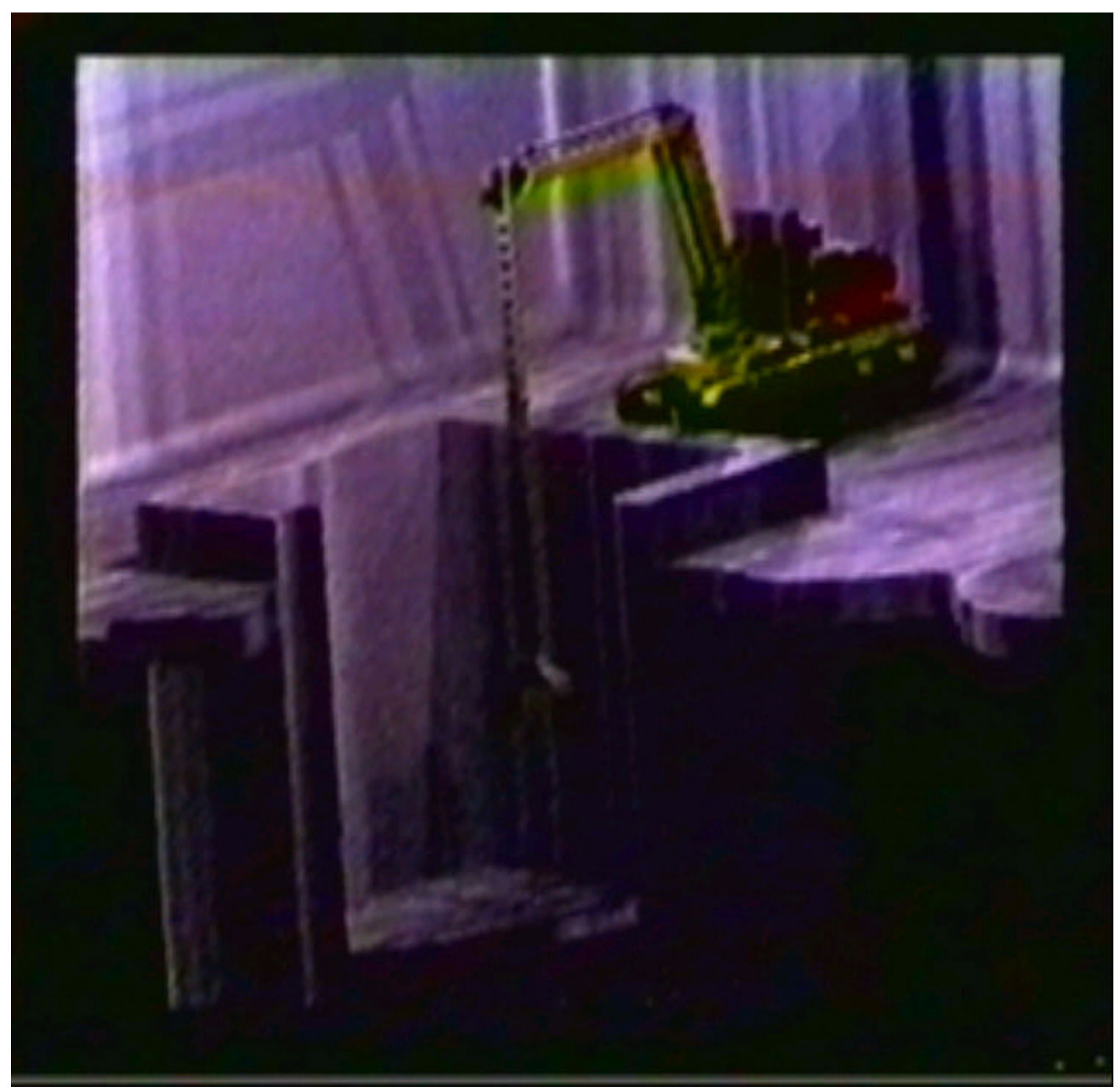

Figure 6.2. Concept 2: MAN-MATE

\subsection{Concept 3}

This system consists of an EMMA modular manipulator deployed on a TETRA robotic platform and two Ingersoll-Rand material handlers (large forklifts) (Figure 6.3). The confinement tent is similar to the existing vinyl tents in use at tank farms only with a closed top. The EMMA manipulator is deployed on one material handler and the TETRA lift platform is deployed by the other material handler. These items work together to operate a selection of tools (cutters, impact wrench, gripper, scoop, torque wrench, spray wand, etc.) and complete the pit clean out. 


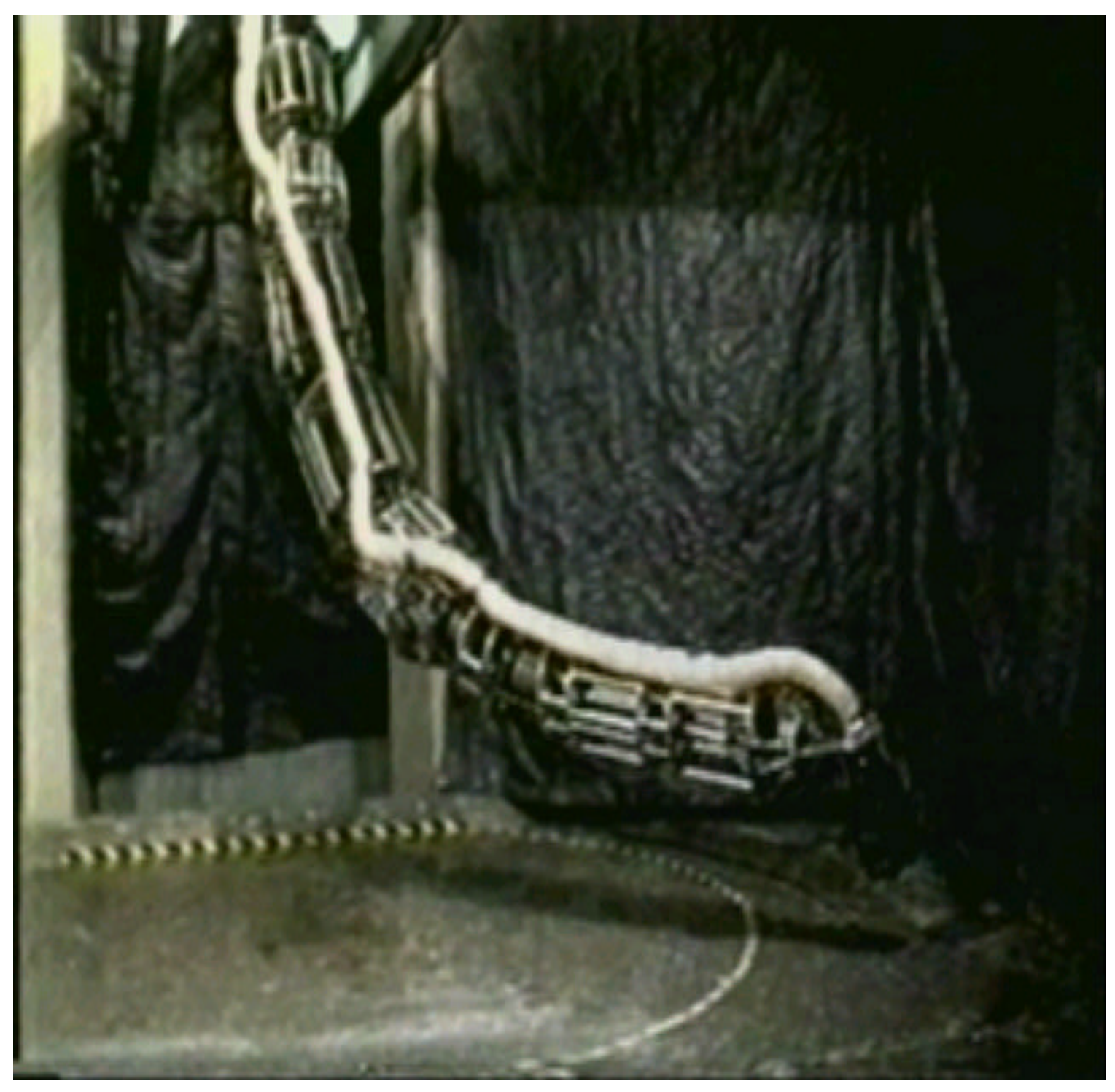

Figure 6.3. Concept 3: EMMA Manipulator

\subsection{Concept 4}

This concept is based on equipment manufactured by Kiebler-Thompson (KT) of Bristol, Pennsylvania (Figure 6.4). KT manufactures a complete line of remotely operated equipment for debricking metal production furnaces, ladles, and other refractory equipment. This concept will utilize the KT-30 track mounted demolition machine with a $1000 \mathrm{lb}$. lift capacity at full boom extension and a skid mounted Furnace Descaling Machine (FDM). The two machines are located on opposite sides of the pit and function remotely with a number of interchangeable tools (shear, grabber, water jet, bucket, scraper, 


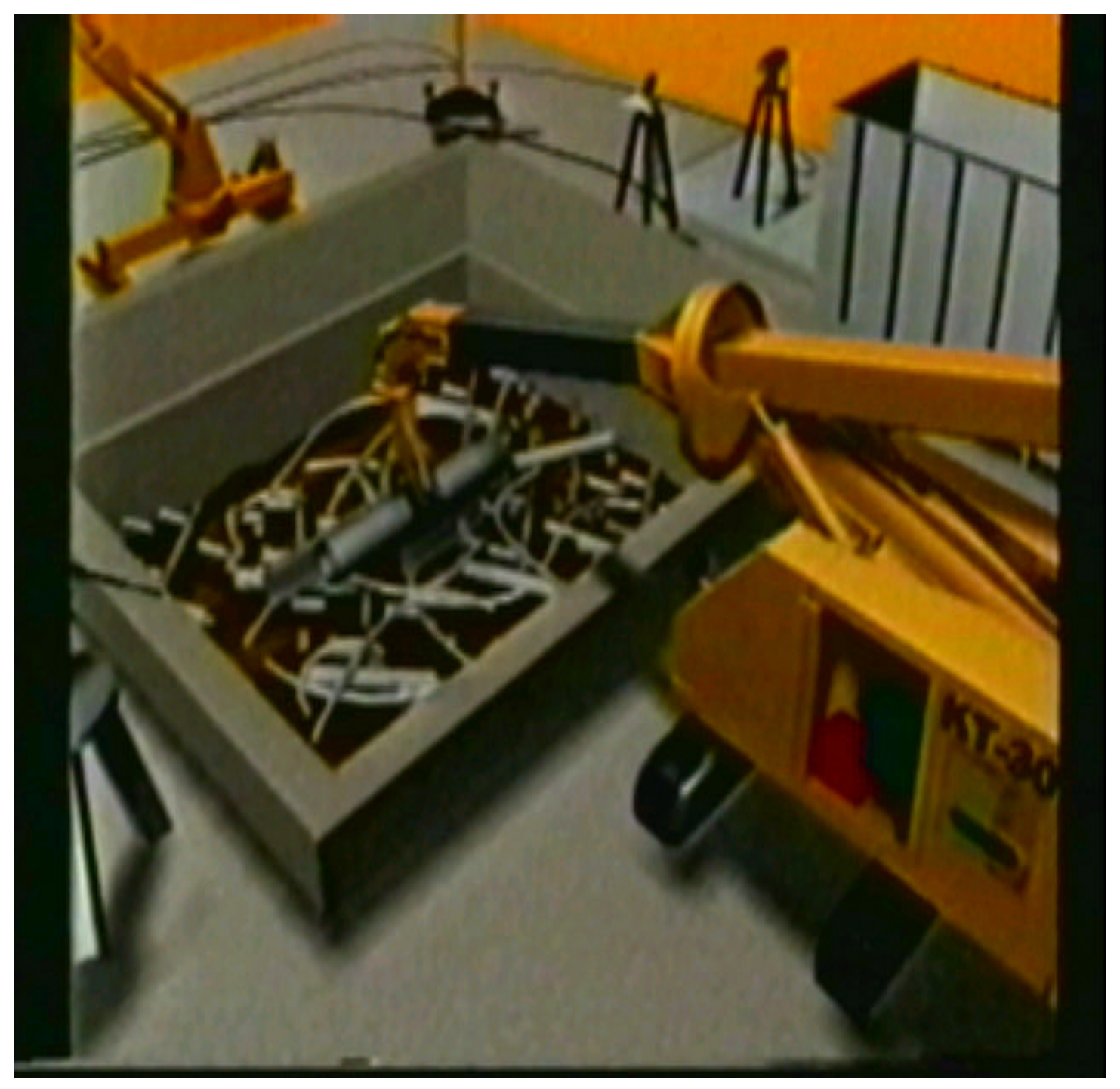

Figure 6.4. Concept 4: KT-30 Demolition Machine with Furnace Descaling Machine

etc.) to accomplish the pit refurbishment tasks. The confinement system is a typical Hanford vinyl enclosure on a pipe frame, although the proposed enclosure is considerably larger than those normally used (43-foot by 35 -foot by 20 -foot high). 


\subsection{Historical Data-Other Sites}

A series of phone calls and discussions with operations and project staff at other sites was completed to assess the current state of technology throughout the Department of Energy (DOE) complex.

\subsection{Oak Ridge}

Oak Ridge has reactor off gas-filter pits, which are not similar to Hanford jumper pits. No one has operated in them for quite some time, and there is no current driver for remediation.

\subsection{Idaho}

There are about five filter pits, which are part of the reactor off-gas filter system. These pits are approximately 6-feet square and 10 feet deep. They are mostly filled with a vessel containing an absorbent material. The pits are outdoors, underground, and have heavy covers. The absorbent vessel is cylindrical. Two other pits are similar, but bigger. Radiation levels in these pits are not particularly high, but there are confined space issues.

Idaho also has process cells, which are approximately 20 -feet square and between two and five stories tall, depending on the cell. Most of these cells extend 10 feet above grade. They have 5-foot-thick concrete tops. The current disposal plan is to remotely remove everything in the cell that is above grade, fill the cell with grout, spray fixative inside and remove the top. Items to be removed include 3-inch pipe and 6-inch-diameter pressure vessels.

\subsection{Savannah River}

Savannah River has a few underground pits similar to the Hanford tank pits. In general, the Savannah River engineering staff has developed some specific tools for use in those pits, but no general-purpose remote technologies. The structures are referred to as pump pits, diversion boxes and valve boxes. Specific tool developments at Savannah River included a vacuum system for a valve box.

Savannah River has built one-time-use type tools. They have proposed gantry type systems but have been turned down based on development cost. They have put together a stereo vision system, but it has never been used. The operations culture, operating environment, constraints and the activities performed appear to be very similar to those at Hanford.

\subsection{Los Alamos}

No information available. 


\subsection{Fernald}

Pits at Fernald are roughly 40 acres in area and 4 feet deep. They are more like landfills than Hanford pump pits.

\subsection{Rocky Flats}

Rocky Flats does not have pits.

\subsection{Similar Remote Applications within the DOE Complex}

Many of the tasks that need to be done in the cells in the Hanford canyon buildings for characterization or manipulation of components are very similar or even identical to those associated with tank pits. The width and length of the cells are very similar to many pits, while the depth of canyon cells tends to be somewhat deeper than the pits. The same types of connector and jumpers are used in both pits and cells. The PUREX connector was developed initially for cell applications. Similar savings in reduced exposure and improved efficiencies would be realized for cell operations.

There are also similar remote systems needs and requirements for work planned or going on in the 324 B-cell at Hanford, and the retrieval of waste from the mixed waste caissons at Hanford.

\subsection{Summary}

The project has not been able to identify a similar problem for pit refurbishment at non-Hanford sites, of nearly the same magnitude. Idaho has half a dozen pits, but they are not nearly as complex inside and are very low radiation hazard. Savannah River has a few pits that may be quite similar to Hanford in terms of operations, contents and physical geometry. Because these structures are few in number and little is done with them, no general-purpose technology has been developed to support them. However, general-purpose tools may be useful if they were available. Application of remote systems for pit refurbishment would likely have direct application to canyon cell work. 


\subsection{Classes of Potential Remote Systems Solutions}

In attempting to address options, the RBX project team began by identifying potential classes of solutions. Six major classes were identified: gantry with manipulator and jib crane, out-of-pit telescoping boom with manipulator, fixed structure/tower (stationary frame) with a long-reach manipulator, in-pit vehicle/mobile platform with manipulator, crane-mounted platform, and manipulator on stationary mount inside pit. A brief description of these classes of solutions is presented below.

In each case, all tools are picked up and operated by the gripper. The gripper is considered part of the manipulator and not a separate tool/end-effector. In addition, a jib crane is a support "accessory" to just about every class-with it being the most important with Class 1. A jib crane would allow pit operations to be less dependent on Tank Farm cranes, which are a scarce resource.

1. Gantry Robot with Manipulator and Jib Crane. This concept is a gantry (mobility in the structure) with a telescoping z-mast, a manipulator mounted on it, and a jib crane. The gantry is used to support and position the manipulator/mast combination. The gantry provides motion capabilities in the horizontal plane. The gantry permits the mast-mounted manipulator to be positioned over any desired location in the pit. The mast is connected to the gantry and protrudes above the top of the gantry when the mast is in the fully up position.

The manipulator has a reach of approximately 4 to 6 feet and a payload of approximately 300 to $500 \mathrm{lb}$. A Conan manipulator is an example of the type of manipulator being considered. The manipulator will be used for most tasks in the pit. The gripper will be used to either manipulate (grasp) objects or grasp tools to complete tasks. Most tasks will be done using only the manipulator but some will be completed working in cooperation with the jib crane.

To keep the size of the gantry as small as possible, a jib crane is used to move material in and out of the pit. The jib crane will have a powered rotation, and the hoist will be powered along the jib boom. The hoist will have a hook at the bottom end for connecting to transfer containers, impact wrenches, and other items.

Options to basic concept:

The manipulator could be a 3-DOF wrist, a 6-DOF manipulator, or a long-reach arm such as a Stewart platform, VGT, or EMMA, etc.

The gantry bridge can be at the pit level or above it. At pit level, the gantry is not used to move items into or out of the pit. Those functions are performed using the jib crane. The rails of the gantry are positioned only high enough above the pit to permit clearance over in-pit hardware by the manipulator when the mast is in the fully up location. The short gantry legs mean that there is less area that needs to be contained. The gantry needs to be designed so that it does not need a high level of accuracy and alignment for setup. 
The gantry can have $\mathrm{X}, \mathrm{Y}, \mathrm{Z}$ motion, or $\mathrm{Y}, \mathrm{Z}$ motion.

2. Out-of-Pit Telescoping Boom with Manipulator. This concept is a telescoping boom mounted on a fixed, wheeled, tracked, or skid device (backhoe, tractor, ROSIE, etc.) for gross positioning, with a 3-DOF wrist or 6-DOF manipulator for fine movement.

The boom platform provides a stable platform for the dexterous manipulator to work from. A dexterous robot capable of lifting 300 to $500 \mathrm{lb}$. would allow many operations to be completed in the pits. It would also be advantageous if both devices came with standard control systems that could be used right out of the box.

This system is also easily deployable. Operations would simply drive or crane-position the boom platform into the site, park it at the side of the pit, and extend the boom close enough to the pit to allow the dexterous robot to do the work. Once positioned, the dexterous robot is moved with its own controller to perform operations. A more advanced system could be developed that would control both the boom platform and the manipulator, allowing more efficient operation. In this case, the boom would not have to be repositioned when the work area became out of range for the dexterous robot.

A variant on this would be Stewart platform as the deployment platform with a manipulator on the end of it, or a VGT as the deployment platform.

3. Fixed Structure (Stationary Frame) with Long-Reach Manipulator. In this concept, the platform is fixed to the ground, either with shear weight, or by using tie downs that would attach to buried mounting points. The structure would be high enough to permit a long-reach manipulator to access all parts of the pit, and would be moved into position with a large crane.

The manipulator would have a large enough workspace to reach into the pit from the fixed base. It could be an EMMA, VGT, Stewart platform, etc. The base could have a cantilevered beam that would hold the base of the robot close to the pit, or the manipulator could simply be long enough to reach from the base of the mount to the pit area.

An example of this type of system is the modified light duty utility arm (MLDUA) used by Oak Ridge National Laboratory (ORNL) to clean out the Gunite tanks. This manipulator is mounted on a skid, which is positioned by a crane.

4. In-Pit Vehicle/Mobile Platform with Manipulator. This concept uses a small vehicle that can be placed directly into the bottom of the pit and maneuver around to accomplish the tasks. The vehicle can be tracked, wheeled, or a walker, and could have a plow blade and/or manipulator mounted on it. Examples include Houdini and Dante (multi-legged). 
5. Crane-Mounted Platform. This concept considers a single or dual arm manipulator system, cranemounted. It consists of a base platform deployed from an existing crane. The base platform is equipped with one or more 6-DOF hydraulic manipulators, stabilization mechanisms (such as actively controlled guy wires, counterweights or simplified grippers for grappling hard points in the pit) and a tool rack for carrying various tools.

Options to basic concept:

Use multi-tentacle arms for carrying loads, positioning components, and removing debris. These manipulators would be 2.5 to 3 feet long with four to six per platform.

6. Manipulator on Stationary Mount Inside of Pit. This concept utilizes a 6-DOF manipulator mounted to a platform that rests on the pit floor. It is placed in the pit by a crane, and moved around by the crane to work in specific sections of the pit.

\subsection{Evaluations}

In attempting to evaluate these potential systems, each was broken down into base components-platforms and manipulators. This led to an evaluation of 13 platforms and 12 manipulators.

Platforms:

1. Gantry robot

2. Grade-level gantry robot (no legs)

3. Gantry positioner, with or without legs

4. YZ gantry

5. Wheeled/tracked vehicle in pit

6. Legged vehicle in pit (spider)

7. Walking platform, no autonomy

8. Fixed platform with boom, out of pit, crane placed

9. Mobile platform with boom, out of pit

10. Fixed platform in pit

11. Crane mounted

12. VGT

13. RoboCrane

Manipulators:

1. LDUA

2. EMMA

3. Stewart Platform

4. DAWP/CP-5/Gemini

5. 3-DOF wrist

6. Conan 


\section{Titan III}

8. Hydra

9. WS\&M

10. Condor

11. Jib crane

12. Multi-tentacle arm

Each were graded independently against a set of first cut criteria, which included: initial (capital) cost, schedule for field ability, reliability, commercial availability, maintainability, interaction with balance of system (integration), initial field setup, acceptability to Tank Farm operations, acceptability to equipment operators, and required support systems. The grade/rank for each criterion are shown below.

\begin{tabular}{|c|c|c|c|}
\hline \multirow[b]{2}{*}{ First Cut Criteria } & \multicolumn{3}{|c|}{ Grade/Rank } \\
\hline & 1 & 2 & 3 \\
\hline A. Cost & $<\$ 300 \mathrm{~K}$ & $\$ 300$ to $800 \mathrm{~K}$ & $\$ 900 \mathrm{~K}+$ \\
\hline B. Cold test schedule & $<6$ months & 6 to 12 months & 12 months + \\
\hline C. Reliability & Acceptable & Unknown/doubtful & Unacceptable \\
\hline $\begin{array}{l}\text { D. Commercial } \\
\text { availability }\end{array}$ & Yes & Engineering effort & Development effort \\
\hline E. Maintainability & Acceptable & Unknown/doubtful & Unacceptable \\
\hline $\begin{array}{l}\text { F. Interaction } \\
\text { w/balance of system }\end{array}$ & Plug and play & Some integration & $\begin{array}{l}\text { Significant } \\
\text { development }\end{array}$ \\
\hline G. Initial field setup & Easy & Moderate effort & Substantial effort \\
\hline $\begin{array}{l}\text { H. Acceptable to tank } \\
\text { farm operations } \\
\end{array}$ & Fits in current scope & Some changes & $\begin{array}{l}\text { Significant procedura } \\
\text { changes }\end{array}$ \\
\hline $\begin{array}{l}\text { I. Acceptable to } \\
\text { equipment operators }\end{array}$ & Familiar & Somewhat familiar & Too technical \\
\hline $\begin{array}{ll}\text { J. } & \text { Required support } \\
\text { systems }\end{array}$ & None & Some & Lots \\
\hline
\end{tabular}

Appendix A, Table A.2 shows the actual rankings against the first cut criteria. After going through this ranking exercise, three platforms (legged vehicle in pit, VGT, and RoboCrane) and four manipulators (LDUA, EMMA, Stewart Platform, and multi-tentacle arm) were eliminated from consideration. In each case, the eliminated component scored multiple 3's. The primary drivers for elimination of the platforms were cost, ability to cold test in a reasonable time period, commercial availability, acceptability to Tank Farm operations, and acceptability to equipment operators. The drivers for elimination of the manipulators were cost, ability to cold test in a reasonable time period, reliability, commercial availability, maintainability, interaction with balance of system, initial field setup, and acceptability to equipment operators. 
At this point, tooling requirements were addressed. This was done to evaluate tool-driven performance requirements for the manipulators. Considering the six tasks (jumper handling, size reduction, debris removal, decontamination/fixative application, tool handling, and jumper positioning), a list of tools that are currently, or could possibly be, used during pit operations was developed.

In all cases, the assumption is made that the gripper will hold the tools. All tool utilities (hydraulics, pneumatics, electrical signals, etc.) will be provided by an off-robot umbilical, making the tool a separate entity positioned by the robot but controlled separately. Though tool interface plates can be used, they add complexity to the system, as well as extra cost. It also makes adding new tools to the system more costly, because an interface plate has to be made, and all the utilities for the tool have to connect through the manipulator. All utilities for any tool that may be used, now or in the future, would have to be included in the system. There is such a strong desire by the user to keep the pit operations system as simple as possible, the use of tool interface plates will not be considered.

The following tools were rated against their respective performance requirements. If the tool had no real effect on the design of the manipulator, it was rated with a 1 . If the tool had a moderate effect on the manipulator design requirements, it was rated with a 2 . If the tool required the manipulator to have high precision, was extremely demanding on the manipulator or highly affected the design of the manipulator, it was rated with a 3 . The following is the list of the potential tools and what their performance requirement ranking was.

1. Gripper. This is the most basic tool, and it will be provided with the manipulator. Basic functionality will be provided with a two- or three-jaw gripper. This tool will be able to move debris in the pit, and hold equipment or other tools. Rated a 1.

2. Band Saw. A band saw is currently used to cut 4-inch pipe in the pits. This was rated a 2 because controlling a band saw with a manipulator is a bit complicated, because the cut must be parallel with the blade to prevent breaking the blade during the cut. The band saw must also be sized properly-big enough for the cut but not so big that it cannot be positioned properly.

3. Oxygen-Acetylene Torch / Plasma Torch. This is a possible tool, but is not currently used in the baseline. This was rated a 2 because of positioning requirements.

4. Laser Cutter. This is a possible tool, but is not currently used in the baseline. This was rated between a 2 and a 3 because of positioning requirements.

5. Cutoff Wheel Circular Saw. This was rated a 2 because controlling a cutoff wheel with a manipulator is difficult. The saw can easily break if not aligned correctly. A cutoff wheel must also be sized properly - big enough for the cut, but not so big so that it cannot be positioned properly.

6. Shear and Jaws of Life. These were rated as a 2 because of reaction forces and torques.

7. High and Low Pressure Water Spray. These are currently used for decontamination in the pits. These were both rated a 1 . 
8. Sand Blaster. This was rated a 1 .

9. $\mathrm{CO}_{2}$ Pellet Blaster. This was rated a 2 because of resistance, length, and temperature rise in the supply line.

10. Fixative Application Equipment (brushes and rollers). These were rated between a 2 and 3 because of positioning requirements.

The remaining tools, dozer/blade, shovel, clamshell, broom, rotary wire brush, scraper, and chemical stripper, were all rated a 1 .

The bottom line in terms of tool-driven performance requirements is that a moderate performance level is required from the manipulator.

\subsection{Possible Systems}

Once the first cut was complete and tooling requirements assessed, a refined list of 15 systems (based on appropriate platform and manipulator configurations) was generated. A brief description of each of these follows. Each concept generally contains a platform or base for a manipulator and a manipulator attached to that base. Only combinations of platforms and manipulators that seem reasonable were included in the following list.

1. Gantry robot with 3-DOF wrist. The largest part of this system is a gantry robot with a rigid X-Y-Z carriage (Figure 8.1). The gantry rests on four legs whose bases are outside of the pit. These legs support rails that run parallel to the pit walls. Between these rails is a carriage that supports a vertical mast. The gantry supplies three orthogonal degrees of motion. Attached to the bottom of the vertical mast is a 3-DOF wrist with a gripper that is used to perform the tasks. The 3-DOF wrist unit consists of three revolute joints, which provide orientation capability for the system (Figure 8.2). The 3-DOF wrist would be mounted to the mounting plate on the z-mast of the gantry. The complete system would have a 6-DOF capability to access any location inside the pit, and the gantry could extend out over the end or side of the pit to accommodate moving items into and out of the pit.

2. Gantry robot with 6-DOF manipulator. The concept is similar to system 1 except that the 3-DOF is replaced with a 6-DOF manipulator. This permits the manipulator to be used without having to be coordinated independently of the gantry. This concept would also provide a higher level of dexterity because of the additional degrees of freedom. Figure 8.3 shows a typical 6-DOF manipulator.

3. Grade-level gantry robot (no legs) with 3-DOF wrist. This is similar to system 1 except that the gantry rails are supported directly on the pit walls and not on legs touching the ground outside the pits. Because the rails are at or near ground level, the concept will need a jib crane or other device to move material into and out of the pit. Figure 8.4 shows a grade-level gantry. 


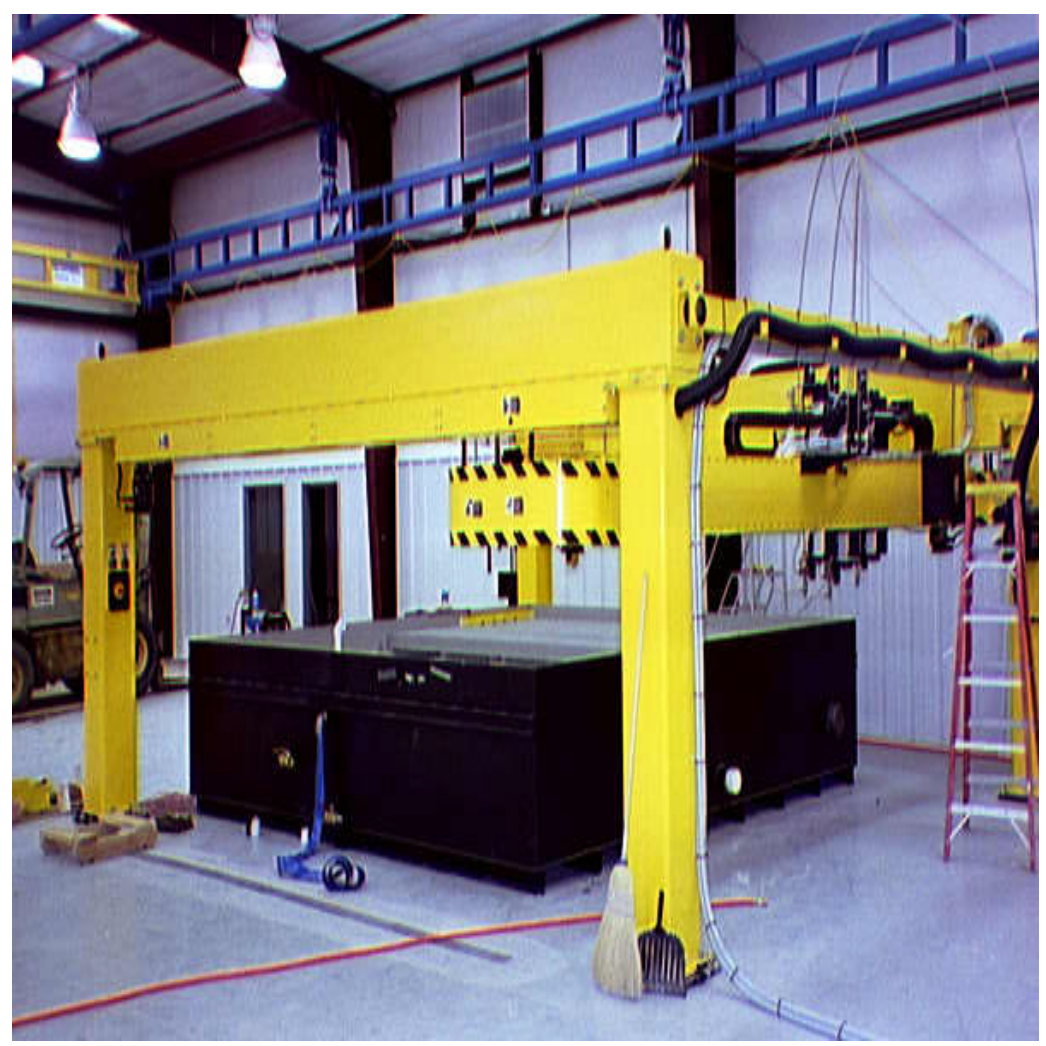

Figure 8.1. Fixed Gantry Robot

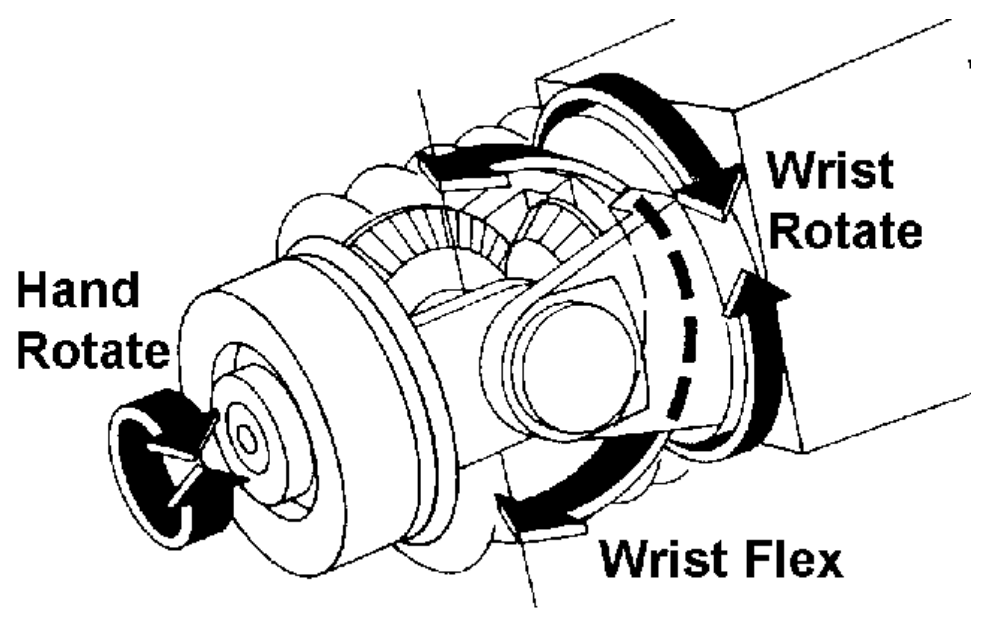

Figure 8.2. 3-DOF Wrist for Gantry Mast or Manipulator 


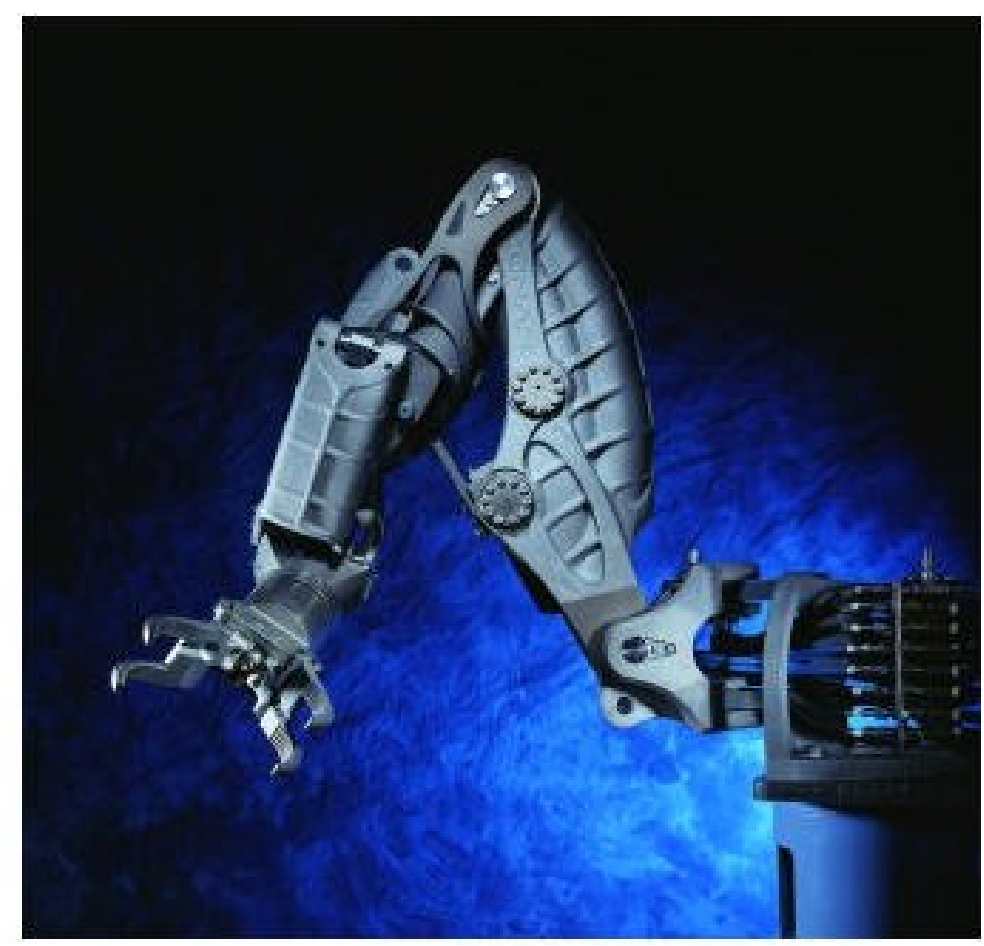

Figure 8.3. 6-DOF Hydraulic Manipulator

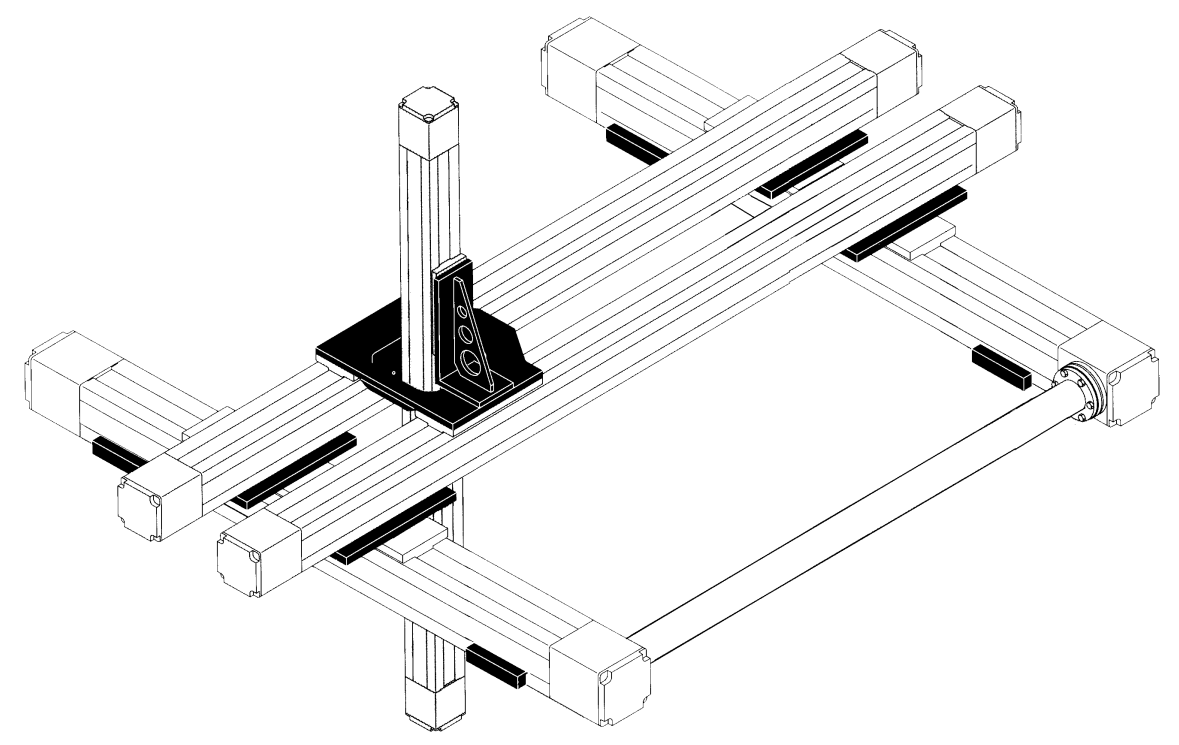

Figure 8.4. Grade-Level Gantry 
4. Grade-level gantry robot (no legs) with 6-DOF manipulator. This is the same as system 3 except that the 3-DOF wrist is replaced with a 6-DOF manipulator.

5. Gantry positioner with 6-DOF. Whereas system 2 has a 3-DOFgantry robot, this system replaces the gantry robot with a gantry positioner. The difference between a gantry robot and a gantry positioner is that a positioner is less precise and not intended for computer control. This gantry would only be used to move the 6-DOF manipulator into position and would be fixed while tasks are being performed.

6. YZ gantry with 6-DOF. This concept is similar to Concept 2 except that it is intended for pits that are narrow enough that motion across the pit width is not required.

7. Mobile vehicle in pit with 6-DOF. The mobile in-pit platform with 6-DOF consists of either wheeled or tracked vehicles with a standard 6-DOF manipulator mounted on it. A system similar to this is the Houdini system used in the ORNL tank cleanup program. Tracked or wheeled vehicles could be used depending on the environment and the condition of the pits. If the vehicle were to climb over debris in the pits, a tracked vehicle could successfully navigate the environment. If the pit is relatively clean of major debris, a wheeled vehicle might offer a better solution. Figure 8.5 shows a mobile vehicle with a 6-DOF manipulator.

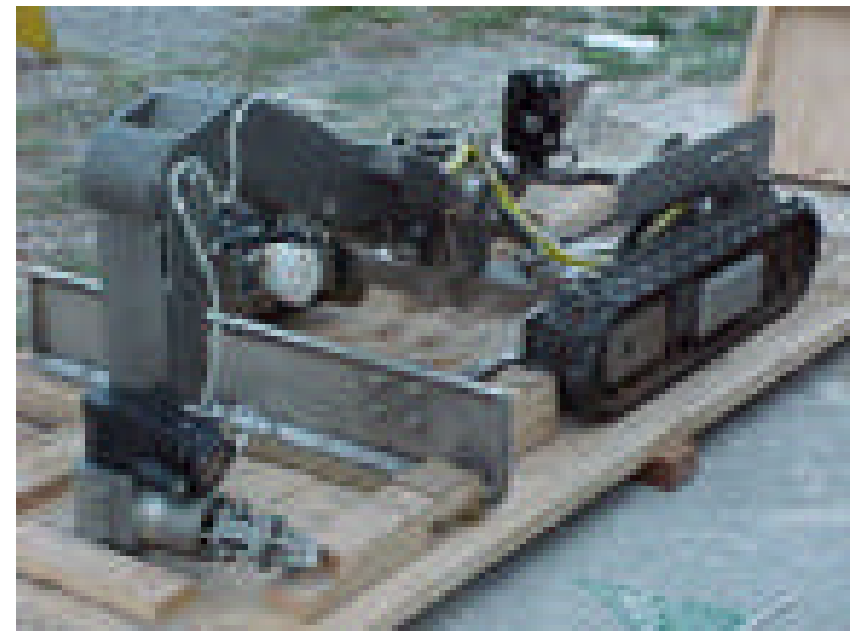

Figure 8.5. Mobile Tracked Vehicle with 6-DOF Manipulator

8. Walking platform in pit with 6-DOF. This system is similar to system 7 except that instead of a wheeled or tracked vehicle, the manipulator would be mounted on a fairly simple platform with movable legs or mechanisms that would permit repositioning of the device.

9. Fixed platform with boom, with 3-DOF, out of pit (crane place). This system consists of a boom such as a knuckle boom crane with a 3-DOF wrist mounted on the end. The base of the boom would be placed in position by a crane. The motion of the boom and the wrist would be coordinated to provide a full six degrees of freedom. 
10. Fixed platform with boom, with 6-DOF, out of pit (crane place). This system is similar to system 9 except that a 6-DOF manipulator is mounted on the end of the boom instead of the 3-DOF wrist. The boom would only be used to position the manipulator, which would eliminate the need for coordinated motion with the boom.

11. Mobile platform with boom, with 3-DOF, out of pit. This system is similar to system 9 except that the base could be wheeled or tracked (i.e., a backhoe) and be driven into place.

12. Mobile platform with boom, with 6-DOF, out of pit. This system is the same as system 10 except that the base could be wheeled or tracked and be driven into place.

13. Fixed platform in pit with 6-DOF. This system consists of a fixed base with a 6-DOF manipulator mounted it. The base and manipulator pair would be placed into location by an overhead crane and repositioned by the same crane, if needed.

14. Crane mounted platform with 6-DOF. This system consists of a 6-DOF manipulator mounted to a platform suspended at the desired location from an overhead crane. The platform would be stabilized with guy wires, grippers, or others means. There might also be a package of on-platform sensors to characterize its motion and modify the motions of the manipulator to compensate.

15. Crane-deployed DAWP/Gemini. Similar to system 14 except the suspended system is the commercially available dual arm work package.

\subsection{Second Cut-System Ranking of Task Abilities}

To compare these various system concepts, the six pit operations tasks were reviewed, and each system was graded as to its ability to perform each task. The tasks are jumper handling, size reduction, debris removal, decontamination/fixative (spray only), tool holding (including brush and roller), and jumper positioning. If the system was thought to be able to perform the task very well, a score of 1 was given. If the system could only do the task moderately well, a score of 2 was given. For tasks that could not be performed or only performed marginally, a score of 3 was given. For all practical purposes, a score of 3 on any task indicated the system was not acceptable. Appendix A, Table A.2 shows the ranking table for this evaluation.

1. For Task 1, jumper handling, the three in-pit concepts (wheeled/tracked vehicle, walking platform, and fixed platform) all got a score of 3 because it was felt that they did not have the reach ability required because they are all sitting on the floor of the pit. The crane-mounted 6-DOF manipulator got a score of 2 because of concerns about stability of the platform. All other concepts scored a 1.

2. For Task 2, size reduction, all systems received a score of either a 1 or 2. 3-DOF wrists and platforms resting on the bottom of the pits scored a 2 because of either reach or dexterity concerns. All other concepts scored a 1. 
3. For Task 3, debris removal, the fixed platform in pit concept scored a 3 because of reach concerns and the need to reposition the platform several times. 3-DOF wrists and platforms resting on the bottom of the pits scored a 2 because of either reach or dexterity concerns. All other concepts scored a 1 .

4. For Task 4, decontamination/fixative application, the concepts with platforms sitting on the pit floor scored a 2 because the potential for limited access while all the rest scored a 1.

5. For Task 5, tool handling, all concepts were rated either a 1 or 2 . The concepts receiving a score of 2 did so because of concerns about dexterity.

6. For Task 6, jumper positioning, gantry-based systems all received a score of 2 because of potential interference with the crane supporting the jumper. Concepts that sit on the pit floor also received a score of 2 due to potential reach limitations. All other concepts were scored a 1.

For each concept, the scores for each task were totaled. Total scores ranged from 6 (best) to 13 (worst).

\subsection{Additional Second Cut Criteria}

Next, the 15 systems were ranked against three additional criteria. These were cost, schedule, and necessary auxiliary equipment. The cost of the system was estimated and scored as follows: less than $\$ 0.5 \mathrm{M}$ scored 1, between $\$ 0.5 \mathrm{M}$ and $\$ 1.0 \mathrm{M}$ scored 2, and over $\$ 1.0 \mathrm{M}$ scored a 3. While there is some uncertainty about capital funding, the assumption was made that most likely between $\$ 0.5 \mathrm{M}$ and $\$ 1.0 \mathrm{M}$ would be available for procurement.

For schedule, systems that could be ready for testing in less than 6 months scored a 1 , systems that were felt to be to the testing phase in 6 to 12 months scored a 2 and systems requiring more than one year scored a 3. It was assumed that it would be necessary to field a demonstration system within a fiscal year or at least have all the components assembled and ready for testing by the end of a fiscal year.

For required auxiliary equipment, systems that required equipment such as large cranes scored a 3, while systems requiring only a minimal amount of support equipment such as a small crane scored a 2 and concepts requiring no support equipment scored a 1 . The auxiliary equipment category was not considered as important as cost, schedule, or the ability to perform tasks.

Appendix A, Table A.2 shows the results of this scoring. Any system that scored a 3 in either cost or schedule was eliminated because it would not be possible to field such a system under the current programmatic constraints.

Six of the 15 concepts that made it past the first cut were eliminated as a result of the second cut. Concept 3, grade-level gantry robot (no legs) with 3-DOF manipulator, was eliminated because of an unacceptable score on ability to perform tasks. This concept has reach and dexterity issues with several of the tasks. 
Concept 5, gantry positioner with 6-DOF, was eliminated primarily because of schedule concerns. It is believed that a gantry positioner, as required for the pit refurbishment tasks, does not currently exist and would require considerable developmental effort, which did not seem possible in the time available.

Concepts 7 (mobile vehicle in pit with 6-DOF), 8 (walking platform in pit with 6-DOF), and 13 (fixed platform in pit with 6-DOF), were eliminated because of task scores. All of these concepts have difficulty performing some tasks. Because they all sit on the bottom of the pits, they tend to have limited reach capabilities.

Concept 15, crane-deployed DAWP/Gemini, was eliminated for cost and the required auxiliary equipment.

When the remaining nine concepts were examined, all seemed to pass a sanity check as being concepts that had a reasonable chance of performing all of the required tasks within the cost and schedule constraints that exist.

For purposes of writing up the nine system concepts in greater detail, some of the gantry-based concepts were grouped together (Systems 1 and 2). While each gantry-based concept is different, there are many variations on the theme that could apply to most concepts in this category. Concepts $9,10,11$, and 12 were also combined because their only differentiation was how the base was supported, and whether they used a 3-DOF wrist or a 6-DOF manipulator. This left five system concepts. These are Gantry-Based Systems with 3- or 6-DOF, Grade-Level Gantry with 6-DOF, YZ Gantry with 6-DOF, Boom with 3- or 6-DOF, and Crane-Mounted Platform with 6-DOF Manipulator. 


\subsection{Detailed Discussion on the Final Five Potential Concepts}

\subsection{Gantry-Based Systems with 3-DOF Wrist or 6-DOF Manipulator}

A three-axis gantry robot provides full coverage of the open pit. The layout for the gantry robot could extend beyond one side of the pit if the gantry robot is to be used to remove material from the pit or is used to bring equipment into the pit. The gantry robot would provide the Cartesian $\mathrm{X}, \mathrm{Y}, \mathrm{Z}$ positional capability for the mast end plate.

A 6-DOF manipulator would be attached to the end plate of the mast. The 6-DOF manipulator would provide the dexterous capability to allow an end-effector to be oriented and positioned when working in the pit.

If a 3-DOF wrist is used instead of the 6-DOF manipulator, it too would be attached to the end plate of the mast. The 3-DOF wrist would provide the capability to allow an end-effector to be oriented properly when positioned by the gantry robot.

An optional component to the system is to provide some limited crane lifting capability. This can be accomplished in two ways. First, a second bridge could be added to the gantry robot, either on a second set of rails above the primary robot rails or on the same rails as the robot. From the trolley on the new bridge, a cable hoist would be used to transfer items into or out of the pit. A second possibility is to use a powered jib crane mounted to one of the legs of the gantry robot, or it could stand-alone.

The three-axis gantry with the attached 6-DOF manipulator would provide a redundant 9-DOF robot. In this configuration, the gantry robot would be used for gross positioning and the 6-DOF manipulator would be used to perform the tasks. The three-axis gantry with the attached 3-DOF wrist would provide a complete 6-DOF robot. Attached to the tool interface plate of either, would be a standard two or three jaw gripper. The gripper would be used to grab items for moving, positioning or using tools to perform the necessary work.

Initial set-up of the gantry robot could be performed with two possible approaches. The first approach would entail pouring concrete pads at the locations of the support legs. The support legs would be placed onto the support pads and secured into place. The rails and the bridge would then be attached into place and the assembly process for the remaining components would follow. The second approach would be to build a gantry robot that was structurally rigid enough to be placed over the pit with a crane, and powered jacks at the corners would be used to level the gantry robot assembly.

\subsection{Grade-Level Gantry with 6-DOF Manipulator}

This is a three-axis gantry system with no legs that is mounted on top of the pit walls. It provides full coverage of the open pit. The pit walls support the gantry bridge rails. The gantry robot would provide the Cartesian X, Y, Z positional capability for the mast end plate. 
A 6-DOF manipulator would be attached to the end plate of the mast. The 6-DOF manipulator would provide the capability to allow an end-effector to be oriented and positioned properly.

An additional lifting system is required to provide some ability to remove items from the pit. This can be accomplished in two ways. First, a second bridge could be added to the gantry robot, either on a second set of rails above the primary robot rails or on the same rails as the robot. From the trolley on the new bridge, a cable hoist would be used to transfer items into or out of the pit. A second possibility is to use a powered jib crane independently mounted as a stand-alone device.

The three-axis gantry with the attached 6-DOF manipulator would provide a redundant 9-DOF robot. Attached to the tool interface plate at the free end of the manipulator would be a standard two or three jaw gripper. The gripper would be used to grab items for moving, positioning or using tools to perform the necessary work.

Initial set-up of the gantry robot could be performed using the following approach. The first step in the procedure would be to mount the rails to the top of the pit walls. The bridge would then be attached in place and the assembly process for the remaining components would follow.

\subsection{YZ Gantry with 6-DOF Manipulator}

A two-axis gantry robot provides linear coverage of the open pit. The layout for the gantry robot could extend beyond the side of the pit, which is associated with the Y-axis, if the gantry robot was to be used to remove material from the pit or was used to bring equipment into the pit. The gantry robot would provide the Cartesian Y, Z positional capability for the mast end plate.

A 6-DOF manipulator would be attached to the end plate of the mast. The 6-DOF manipulator would provide the capability to allow an end-effector to be positioned and oriented properly by the robot.

An optional component to the system is to provide some limited crane lifting capability. This can be accomplished in two ways. First, a second bridge could be added to the gantry robot, either on a second set of rails above the primary robot rails or on the same rails as the robot. From the trolley on the new bridge, a cable hoist would be used to transfer items into or out of the pit. A second possibility is to use a powered jib crane mounted to one of the legs of the gantry robot or as a stand-alone device.

The two-axis gantry with the attached 6-DOF manipulator would provide a redundant 8-DOF robot. Attached to the tool interface plate would be a standard two or three jaw gripper. The gripper would be used to grab items for moving, positioning or using tools to perform the necessary work.

Initial set-up of the gantry robot could be performed with three possible approaches. The first approach would entail pouring concrete pads at the locations of the support legs. The support legs would be placed onto the support pads and secured into place. The rails and the bridge would then be attached into place and the assembly process for the remaining components would follow. The second approach 
would be to build a gantry robot that was structurally rigid enough to be placed over the pit with a crane, and powered jacks at the corners would be used to level the gantry robot assembly. The third approach would be to utilize a wheeled gantry.

\subsection{Telescoping Boom with 3-DOF Wrist or 6-DOF Manipulator}

These two concepts use a telescoping boom with a base that can be mobile, such as a wheeled or tracked vehicle, or it could be a fixed base that is placed using the same crane that is used to remove the cover blocks from the pits. Both concepts have the base positioned near the pit but not touching the pit wall. The difference between these two concepts is the way the boom is used. For the concept using the 6-DOF manipulator mounted on the boom, the purpose of the boom is just to position the base of the manipulator in a useful location in the pit. Once in position, the boom does not move until the manipulator needs to be repositioned. The boom and manipulator are not intended to be used as highly coordinated manner. For the concept with a 3-DOF wrist on the end on the boom, the boom is intended to be used in a coordinated manner with the wrist to provide all six degrees of freedom needed. In effect, the boom/wrist combination will act as a 6-DOF manipulator. The operator would switch between operating the boom and the manipulator, and not control both at the same time. While this concept is made up of components from two different sources (one for boom and one for wrist), they need to be integrated into a device that appears to be a single unit to the operator.

The 6-DOF concept does not currently exist as a complete commercially available system. However, it would require much less integration than the 3-DOF Wrist System. The 3-DOF Wrist System requires the coordination of degrees of freedom of the boom and the wrist and significant changes to the boom hardware. The 6-DOF Manipulator System would be operated much differently. The boom would be used only to position the manipulator at the desired location in the pit and the 6-DOF manipulator used to perform tasks with the boom fixed in position.

The primary advantages of the 3-DOF concept is that it will be able to develop a wrist and boom combination that is specifically designed to the tasks to be performed, with the full range of reach and payloads. One disadvantage of this concept is higher initial costs because it involves a substantial development effort.

The primary advantage of the 6-DOF concept is that all required tasks will be able to be completed with a system that can be positioned outside of the pit, and the system is very cost competitive with other remote systems of similar capabilities.

In both cases, there is a disadvantage in interfacing the boom with a containment structure.

Reach. 3-DOF System. This is a "to be developed" item during integration of a boom and a 3-DOF wrist. The reach can be anything within reason and none of the pit dimensions presents a particular challenge. Clearly, being able to reach 14 feet (widest pit on list) and 10 1/2 feet down (deepest pit) with a payload of several hundred pounds is well within the capabilities of existing boom technology. However, there is a trade-off between reach and precision of this concept. It is possible for this concept to have a boom with a reach capable of accessing any location in any pit with exception of locations 
shielded by intervening items. However, with a very long boom, precise motions of the end-effector using the actuators on the boom will be more difficult. Because the boom is simply an adaptation of a conventional piece of heavy equipment, the actuator components might be replaced with more controllable devices and displacement-measuring devices added to each degree of freedom. There will also be trade-offs between reach/payload and system weight. The longer the reach and the larger the payload, the larger the total weight of the equipment will have to be to provide the strength and stability required.

6-DOF System. The reach of this concept is primarily determined by the boom that is selected. A boom reach capable of positioning the manipulator in a satisfactory working location for all pit dimensions does not present a problem. Once in position, the boom will be "locked" and not moved while the manipulator uses its gripper and tools to complete the tasks. The orientation of the manipulator on the end of the boom may not be the same as normally envisioned. Because we will be predominately working below the manipulator base, rotating the base 90 to 120 degrees from the conventional arrangement may be required to optimize the reach capability. The only limitations on reach will be the result of equipment in the way, either of the boom arm or on the base situated outside of the pit.

The payload of this concept will be governed by the payload of the wrist or manipulator that is selected. However, a payload of several hundred pounds is feasible. The boom arm itself will have a payload (which includes the weight of the manipulator) that is several times that of the wrist or manipulator.

Initial cost. The 3-DOF wrist on a boom will be more expensive than the 6-DOF manipulator on boom and crane-mounted 6-DOF manipulator, but comparable to gantry systems.

Maintenance requirements and serviceability. The 3-DOF concept will have maintenance and serviceability issues that are more restrictive than the 6-DOF manipulator on the boom because this will be a "first of a kind" integration with probable modifications of the boom hardware. However, in other respects this concept is very similar to the other concepts that are on the short list. After its first use in a contaminated pit, this equipment will be considered as potentially contaminated, and maintenance will be more difficult. However, maintenance will not be significantly different from other concepts on the short list.

Required set up (initial and subsequent). Set up activities will begin once the cover blocks have been removed. The boom and wrist will likely be wrapped in plastic to minimize the risk of contamination of these components. If the boom is mounted to a wheeled or tracked vehicle, the system can be driven into location on or near the side of the pit. Otherwise, the equipment would be placed using the large overhead crane. As envisioned, the boom of the system would penetrate an opening on the side of the greenhouse that might be used for contamination control. Once in position, the umbilicals for power and control will be routed from the base to the operator workstation and the power source. If the system base needs to be repositioned because of reach or interference issues, this would be done with the boom up, out of the pit, to prevent damaging in-pit hardware. During such movement, it may be necessary to bag the end-effector and any exposed parts of the wrist/boom. Once the pit refurbishment work is completed, the equipment will be decontaminated and moved to a suitable storage location. Subsequent set ups will be 
essentially the same as the initial except for possible considerations resulting from potentially contaminated equipment. Set up for this concept would be nearly identical to the set up of the 6-DOF manipulator on a boom, probably less difficult and time consuming than setting up a gantry system, and more time consuming than setting up a crane-mounted 6-DOF manipulator.

Ease of use relative to the other remote systems on the short list. The 3-DOF-wrist concept is probably slightly less easy to use than the 6-DOF manipulator because of the control of the boom portion will likely have less fine control than a 6-DOF arm. For most tasks, it may be slightly harder to use than the gantry options, especially near pit walls. The gantry with its vertical mast will be able to reach many areas with greater dexterity. Tasks requiring an auxiliary crane would be more difficult with a gantry system. A crane-mounted 6-DOF manipulator will have more access potential than this concept, but stability of the manipulator remains an unanswered question. For almost all tasks in the pits that require remote operations, the use of the 3-DOF wrist on a boom will be much easier than using existing methods. The 6-DOF manipulator provides finer control of position and the useful envelope of the gripper is larger. It is not quite as easy to use as the gantry if it is attempting to complete tasks near walls. It might be very similar to the crane-mounted manipulator for ease of use. It is surely much easier to use than current remote practices.

Ease of decontamination. All of the systems on the short list will have similar decontamination issues. It will be possible to wrap most of the boom in plastic to aid in decontamination. It will be possible to design the arm and boom to be compatible with a water wash down for decontamination. The equipment will also be compatible with fixatives. However, as with all mechanical components of this nature, free release of the equipment is very unlikely and will have to be treated as potentially contaminated equipment after the first use in a contaminated pit.

Selection of the 6-DOF manipulator will be critical to addressing decontamination issues.

Robustness. Relative to other options on the short list, this may be the least robust primarily because it will be a "first of a kind" integration effort. However, in all other regards this concept is very similar to the others. The 6-DOF System would be more robust than the 3-DOF.

Spread of contamination in operation. This concept is the least compatible with a containment structure around the pit of all the concepts on the short list. Because the base is outside the pit and the boom is being actively used to manipulate tools to do tasks, sealing around the boom will be difficult. The same issue exists for the 6-DOF manipulator on a boom, except that the boom is normally locked into a fixed position for much of time. The 6-DOF concept is better than the 3-DOF wrist, but more restrictive than the gantry- or crane-mounted manipulators.

The one disadvantage to this system has to do with dome loading. The weight of the boom platform is considerable, and would likely have to be positioned close to one of the tanks. 


\subsection{Crane-Mounted Platform with 6-DOF Manipulator}

This system consists of a base platform deployed from an existing crane. The base platform is equipped with a 6-DOF hydraulic manipulator. This platform would also have stabilization mechanisms (such as actively controlled guy wires, counterweights or simplified grippers for grappling hard points in the pit) and a tool rack for carrying various tools. All active elements on the platform are hydraulically powered by a pump located off the platform. Control signal lines and hydraulic hoses are combined into a single umbilical that is draped from the ground up to the platform.

The manipulator is controlled by a miniature master arm, which the operator manipulates. The slave arm tracks the motions of the master.

Moving counterweights would be under computer control with no operator intervention (other than to turn the system on and off). Stabilizing guy wires or grippers would be under the control of the operator.

In many ways, this system is very similar to current practice. It requires that a crane be available at all times during pit operations, and the crane remains the primary tool for working. The responsibility for finely controlled motion is shifted, however, from the crane to the manipulator system. It is possible that this system will be seen as more cumbersome than the current practice. Rather than going directly to work, the crane will need to pick up the manipulator platform first. However, the manipulator platform has a great deal of utility, and picking and placing the crane platform should be very easy. The operator interface and control system should be very simple and streamlined for this system, lending it to ready operator adoption.

Very little set up is required for this system. The platform itself, a hydraulic power unit, and some operator interface (control) equipment are all that is required. These components simply need to be staged near the pit. To deploy the system the crane picks up the platform and the manipulator operator moves to the operator control station (this is probably a very compact portable unit).

The system requires a minimal number of operators - one for the crane, one for the manipulator system and one or two for support - attaching and detaching stabilizer cables, staging equipment and tools for the manipulator system, etc.

Most of the system will be quite straightforward to decontaminate. Hydraulic cylinders and stabilizer cables that have been extended and then retracted could potentially carry contamination into the interior of the machine, so a system once used in a zone would not be available for free release. However, these systems would only be used in contaminated areas, so this should not be an onerous restriction.

The system would be very portable, because it is easily transported by truck and lifted onto and off the truck by crane. It should not be responsible for any more contamination spread than any other method of doing the same work. 
A properly designed system should be readily accepted by most workers. Key points are to keep the user interface simple, robust and compact. The operator control station must not include a lot of computer systems.

Little additional maintenance should be required. Cranes are already in use on the site and impose an acceptable maintenance burden. The platform would be an additional piece of unique equipment, and so would add some maintenance burden. However, if ease of maintenance is emphasized in the design of the system, the additional maintenance should not be excessive.

There will be some areas that are difficult or impossible to reach with this equipment. It may be possible to reach other areas, but difficult or impossible to stabilize the platform at the desired location because of a lack of hard-points to fix stabilizing cables to. For the most part, this should not be a problem. Most areas of the pits will be readily accessible, and we do not generally need to work in those areas that are not. At this point, it is not clear whether a single 6-DOF device can place a jumper and tighten the Purex connectors without dropping the jumper.

A cable-stabilized system will be familiar to the operators and may be more readily accepted. A cable-stabilized system requires anchor points for the cables, and the cables become obstructions for human operators and other pit activities.

This system should be able to reach nearly anywhere that the current baseline system (crane) can reach. In addition, it will have a limited ability to reach under or through obstructions that would completely impede the crane.

The 6-DOF Arm will have a payload of approximately $250 \mathrm{lb}$; it will handle more load with reduced performance. While this is considerably less than the crane without the platform, it should meet the requirements.

Set up of this system should be simple. It would be delivered to the farm on a truck or trailer, the crane would lift it from the trailer and deploy it over the pit as per the operator's directions (operators would anchor the cable ends if cable stabilization is used), the work would be performed, and the platform would be secured and returned to the truck or trailer. It may be somewhat difficult to position the cable anchors properly if operational constraints limit where they can be placed.

The manipulator would be teleoperated. If the cable anchors are well positioned or a non-anchored stabilization technique is used, they will provide no obstacle to operation.

Decontamination. Similar to other systems. Design details and manipulator selection will be key elements of addressing this concern.

Robustness. Depending on design. There is no inherent reason this system should lack robustness relative to other systems of this type. 
Spread of contamination. This should not be worse than existing practice. It does require that some equipment (the manipulator and platform) be bagged for transport between sites or tank farms.

In all cases, the systems can be run with just one operator. Optimal operation would be two operators (one to run the equipment and another to watch the many video feeds). 


\subsection{Commercially Available Boom Systems}

One option that has not been discussed is the purchase of a commercially available boom with endeffector, such as a MAN-MATE or Lamberton Manipulator, perhaps augmented with remote video viewing for the operator. These systems each have different configurations that could perform different tasks, and each has different degrees of complexity and costs. However, the commercially available systems will be described only briefly because the project does not consider this a developmental effort so much as a simple procurement within the scope of operations.

Two companies with commercially available pieces of equipment that fit this category have been identified. Three sizes of MAN-MATE industrial manipulators are available from Western Space and Marine and Lamberton also has a similar manipulator. Both companies can provide systems with force feedback controls. These systems are designed for hostile industrial environments and have reach and payloads appropriate for most remote pit refurbishing tasks. Depending on the radiation levels, the manipulator could be operated from the existing cab or could be relatively easily adapted to remote operation using video cameras. Video may be needed in either case because there may not be line of sight from the cab to the end-effector. It may also be possible to add shielding to the cab to reduce exposure while permitting the operator to remain in the cab. Because of the configuration of the booms, these systems may not be able to reach as many locations in the pits or to have the same dexterity as a system specifically designed for pit operations. However, for many tasks they may be a cost-effective means of implementing remote technology. 


\subsection{Balance of System}

In addition to the platform, manipulator, and tooling, there are a number of ancillary components needed. This includes operator interface, cameras and video equipment, control architecture, and sensors. Each component will need to be chosen by a number of criteria, including cost, schedule, operator acceptance, and versatility.

\subsection{Operator Interface}

For the operator interface, there are a number of choices in how to communicate with the pit operations equipment. They range in complexity from simply using individual toggle boxes as delivered by equipment manufacturers, to a fully automated system, which uses a custom interface, and control system. The systems listed below are a compilation of components that make up a system, and some components could be shifted between the listings below. However, for the sake of presenting ideas, this list will provide a good baseline from which to make decisions.

1. Individual Control Pendants. The most inexpensive way to control the system would be simply to use off-the-shelf control boxes for each of the components in the system. This would mean that the system would have many wires to the system, each connected to a pendant to control each part of the system. For instance, the system composed of a boom manipulator and a 6-DOF manipulator would have one pendant for the manipulator (such as the mini-master from Schilling), a second pendant from the boom manufacturer, and a different pendant for each of the tools that are used in conjunction with the system. The system would also need to have a pendant for the video equipment to control all cameras. The advantage to this system is that it would be inexpensive to purchase, and each pendant would be robust and proven in the field. The disadvantage of this type of control system is that each pendant would have a different layout, and the operators would have to familiarize themselves with all pendants that might be used with the system. This system would also be difficult to set up and tear down because it would be nearly impossible to keep from tangling wires during operation.

2. Custom Control Pendant with Toggle Switches (Joint Movement). Next in the line of complexity is to fabricate a pendant to control all components of the system using only toggle switches and buttons. This would provide a high comfort factor to the operators, because the pendant would look very similar to the pendants used in control of the facility cranes. This would also be an inexpensive option that would be relatively simple. The buttons would provide joint level movement, meaning that each toggle switch would move one joint at a time. This would be similar to the ANDROS system and would provide some level of movement. This system could be relatively robust, but would require custom software, which always adds a little uncertainty to the system. A disadvantage to this system is ease of use. By moving the robot simply by joints, movement of the robot in any straight line becomes difficult. Cost would be relatively low, because the hardware is very inexpensive for the system, but there would be some time required to interface the control pendant with the control systems for the individual manipulators and components. This system would probably not fully integrate the video components of the system into the main pendant, because it is 
convenient to have the video switchbox near the video monitor for selection and manipulation of cameras. This system would be versatile, because it would be relatively easy to add buttons to the pendant to control future devices. This system would likely interface with low-level control computers provided by the manipulator manufacturers to move each joint. This would allow the use of robust, industry-proven low-level control computers, to provide a robust control system.

3. Custom Control Pendant with a Joystick and Toggle Switches. A variation on the previous theme is to utilize joysticks in a custom pendant to control the manipulators of the system, and still utilize switches where they are necessary. For instance, you could use a 3-DOF joystick with a selector switch that would determine which manipulator would be controlled by the joystick at that time. That joystick would then move whichever robot was selected in Cartesian mode at a rate proportional to the position of the joystick. This would make relatively complex moves easy to complete. The Hanford operators have had experience with joysticks in the past on Light Duty Utility Arm (LDUA) and K-basin manipulator systems. Toggle switches would be integrated into the main control pendant for control of the tooling, but these would simply be switches to turn on or off a device, and would be completely dumb to which device was being turned on. Small light emitting diodes (LED's) would indicate which device was active, and any error conditions. Again, video equipment would probably be an off-the-shelf pendant, because many companies make good equipment for surveillance uses. One disadvantage to this system would be that it would not be possible to move more than one device at a time, because they would share the single joystick.

4. Custom Control Pendant with Dual Joysticks and Toggle Switches. A further variation on the custom control pendant theme is to utilize dual joysticks for control of the manipulator and other components in the system. This would have two advantages. First of all, the second joystick could be connected to the second component (if you have a two-component system such as a boom with a 6-DOF) and both components can be controlled at the same time. Secondly, 3-DOF joysticks come in two styles, one for linear motion and the other for rotation. This would allow the second joystick to be the rotational style, which makes it a little easier to control the wrist of a manipulator. Cost and schedule for this option would be no more than for any other pendant option.

5. Custom Control Pendant with Spaceball. Another option on a custom control pendant would be to utilize a spaceball instead of joysticks. A spaceball provides much better control of a robot because it is a 6-DOF input device, which allows fairly complex movement. However, this device would not be familiar to the operators, and may not be as easy to master as a joystick. The rest of the pendant would be very similar to the ones above. Cost and schedule for the spaceball would be no more than the cost and schedule for any of the other custom pendant options.

6. Custom Control Pendant with Touch Screen. One relatively low-cost interface that is available is a touch screen. Today, touch screens can be purchased for less than $\$ 1000$, and software development on them is not difficult. This would add a very professional looking control panel that would replace all the lights and switches in any of the other pendants listed above. It would provide a lot of power in a small space, because it would have multiple pages that could be switched between to control each part of the system in every detail. It could be used in conjunction with a joystick, dual 
joysticks, or even a spaceball. This system would be very versatile because it would be a simple software change to the system to add devices, and could control tooling in an intelligent manner. Cost and schedule would not be much different from the previous custom pendant options.

7. Computer Screen Control Panel. The final option is to use a computer screen to create the control panel for the robot. This could be running on a Unix computer, or a personal computer (PC) depending on the control architecture. This could be a very informative control screen, and use different pages to control different devices. The advantage of this is that much more information is available to the operator, and the manipulators can be commanded to go to a designated location given by either joint positions or Cartesian coordinates. Another way to get this functionality is through the use of a programmable logic controller (PLC) and Think \& Do software, which allows you to connect to a PC to a PLC running Windows CE, and create very complex interfaces.

The recommendation for the operator interface would be to use a dual joystick design with toggle switches and selector switches for all functions other than robot movement (Figure 11.1). This system would hide the fact that there is a computer controlling the system, and is likely to be accepted by the operators. The system would have all the capabilities needed, but would not have many bells and whistles to break. It would be a rugged system, that also had the capability of being enhanced as needs arose. A spaceball is more capable, but has a longer learning curve, and is less likely to be accepted. The touch screen would likely create too much of an advanced feel, and could be rejected by the operators.

\subsection{Camera/Video}

To control the robots effectively, the operators need to be able to see the work area, and have multiple views to enable the operator to be able to perform the task at hand. Stereo Vision can be used to enhance the depth perception of objects, and is extremely useful at times. Three-dimensional (3-D) models are also nice to have, to allow infinite views so that an operator can see around obstacles. The following are options for how the viewing system can be done.

1. Single Camera Viewing. A single camera in the workspace, if well placed, can allow the vast majority of jobs to be done. The camera and controller would be purchased from a surveillance vendor, and the pendant would be within the operator's reach at the control pendant. However, this does not allow any depth perception, which would make most tasks much more difficult, and some tasks would not be possible. This is the simplest approach, and cost and schedule would be minimal, however it does present a single-point failure point from an operational perspective.

2. Multiple Camera Viewing. The addition of a second camera would greatly improve the operator's effectiveness, especially in tasks that require the manipulator to interact with the environment (i.e., pick up some debris). A third camera would also add capability, four or more allows for single point failures and the operator to choose the best view. All cameras can be controlled using the same control box, which would take up little room in the control area. The cost of multiple cameras would not significantly increase the cost of the system. 


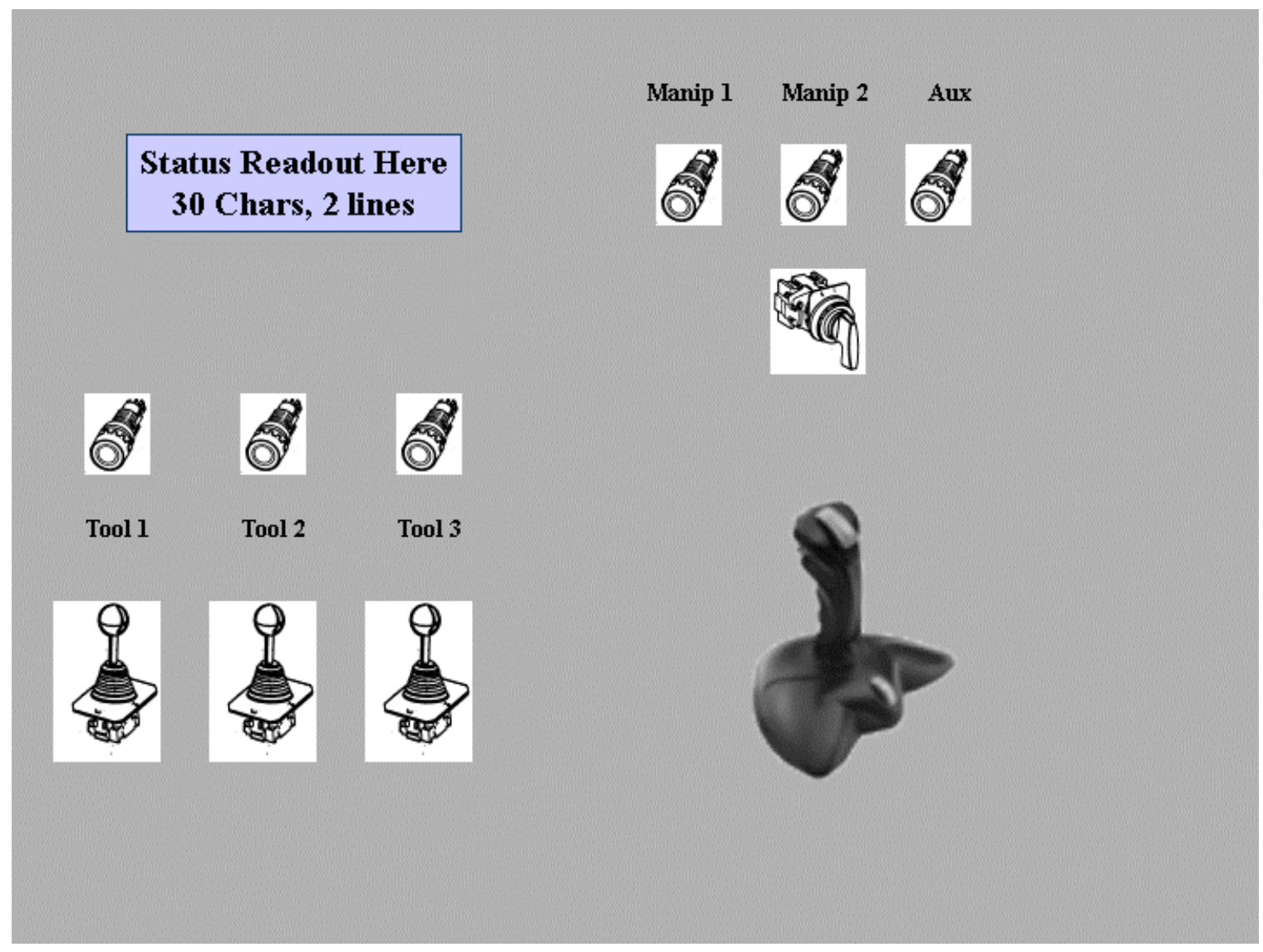

Figure 11.1. Dual Joystick Design with Toggle and Selector Switches

3. Multiple Camera Viewing with Stereo Vision. Recently, stereovision has become more popular, and has uses in 3-D computer-aided design (CAD) rendering, and controlling of devices. The systems are not as expensive as they once were, and are becoming reasonably priced. Stereo Vision simply takes two cameras that are offset by a known amount, displays them on a high-resolution screen, and synchronizes the images with your eyes to give a true 3-D appearance. This adds depth perception to the operator and makes it much easier to interact with the environment. This system is an off-the-shelf product, and would not add much cost to the system. A single stereo camera pair mounted at the end of the manipulator would be very useful during operations. This would require that all tools be configured such that the stereo cameras would have a good viewing angle while they are in place, but that is something that can be worked out with individual tools.

4. Multiple Camera Viewing with 3-D Model. The DOE has spent a lot of time researching 3-D rendering in an interactive environment to allow the operator to view the workspace from any angle, depending on what the task at hand is. This tool is very powerful, but requires an accurate 3-D model of the workspace, and an interface with the manipulator. The 3-D model would have to be produced for each deployment throughout the life of the system. The cost of this system is very expensive, and 
would also increase training requirement for the system operators. The cost is both initial and reoccurring, as each entry into the pit requires a new model and the model changes during operations in the pit.

5. Control Options for the Camera System. Two distinct control options are available for the cameras. First of all, most camera manufacturers can supply pan/tilt/zoom control boxes for their cameras, and they are normal stock items that are produced in mass quantities. These systems are very robust, and are reasonably priced. A second alternative is to control the motors directly using the same computer that controls the rest of the system. This option will allow greater capability, and a more compact control console, but would cost significantly more, and possibly be less reliable.

The recommendation for a camera system is to use a multiple camera system with a pair of stereo cameras on the end of the robot. This system provides a lot of capability, without adding expensive options that are not necessary.

\subsection{Controls Architecture/Integration}

To control the system, a computer is likely necessary to interface with the manipulators in the system. Therefore, a control architecture must be specified that will interface with all computers, as well as the operator.

1. Manufacturer Provided Pendants. In the case of using only the pendants provided by the equipment manufacturers, no computer system would be necessary to control the system. Each component would have its own pendant to control all its functions. This would be the simplest solution, and would be very robust. However, coordinated motion would not be possible, and a pendant would have to be developed for each tool to be used.

2. Non-Computerized System. It is conceivable that a control system could be built that did not use any control computer at all. This would mean that a large pendant would be provided that had toggle switches that controlled all the functions directly. This would mean that each toggle switch would move an actuator on the manipulator directly. No Cartesian movements would be possible with this option.

3. PLC-Based Computer System. In the past several years, PLCs have become much more powerful, and are now a reasonable option for robot system control. Most PLCs do not have the capability to manage many hydraulic servo loops directly, but for this system, that can be handled best by the computers that are provided by the equipment vendors. The PLCs can communicate to those equipment controllers in a high level fashion, and tell the controllers where to move the robot to, but the servo loops will be controlled by the manufacturer's controllers. The PLC is ideal for accepting button and switch inputs, and is capable of interfacing with joysticks as well. The communication with the other hardware controllers is also easily done, so the PLC will simply manage the system. A new advent in PLC design even allows the PLC to use Windows CE as the operating system, which 
makes it much easier to do complex math that would make kinematics routines easier. This system also uses a unique programming method that takes significantly less time to develop the control software.

4. Custom Control System, using a PC. For increased versatility, a personal computer could be used instead of a PLC, as the control console. This could be used to control everything, in a very detailed manner. This option can either use PLC hardware and Think \& Do Software, or Interface Cards in a $\mathrm{PC}$ and custom Visual $\mathrm{C} / \mathrm{C}++$ or Visual Basic software to create detailed control screens for every part of the system. This option could use Windows NT, Widows 95/98, VxWorks, or Linux as its operating system for the control. Windows $95 / 98$ would be the easiest to make things work, but would be the least stable. Windows NT and Linux both have real-time extensions, but were not designed to be real-time operating systems, and are not really proven yet. VxWorks is proven in industry, however, it is very unforgiving to inadequate hardware, and component selection would be very important. This option would also allow automatic recognition of tooling, and provide control screens for each tool. Finally, video monitors could also be controlled by the control screens so that an operator would never have to leave the control terminal throughout control of the device. Unlike the previous options, this option allows the use of the same computer to control the manipulators directly, instead of talking through a low-level control computer. However, the manipulators could be controlled by interfacing with the manufacturer provided low-level computer. This option is costly, but would provide the most flexibility to do any task. Also, training on this type of system would be much more involved than any of the pendant systems.

5. Custom Control System, using a VME-based Computer, and VxWorks. In the past, robot control has been done on VME computers, because the operating system is very robust, and is designed for real-time control. This system would have all the advantages of the previous system, but would use VME computers for the control, and use Sun or PC computers to display the control screens. This advantage would be that the system would have a proven real-time operating system and a dedicated computer system. However, this option would also add significant cost and schedule to the system and would likely make it too complex to be debugged fully. This system would essentially be the same concept as the LDUA control system.

The PLC-based control system is the recommended choice for the control system for the following reasons (Figure 11.2). The PLC-based control system offers most of the flexibility and capability that the PC- or VME-based computer options offer, but at a fraction of the cost. Also, the PLC version provides a stable operating system, and proven technology to ensure that the system will not fail during operation. At the same time, the PLC-based system would not cost much more than either of the non-technical control solutions, but offers far more capability. The PLC version also offers almost infinite expandability for future capabilities. 


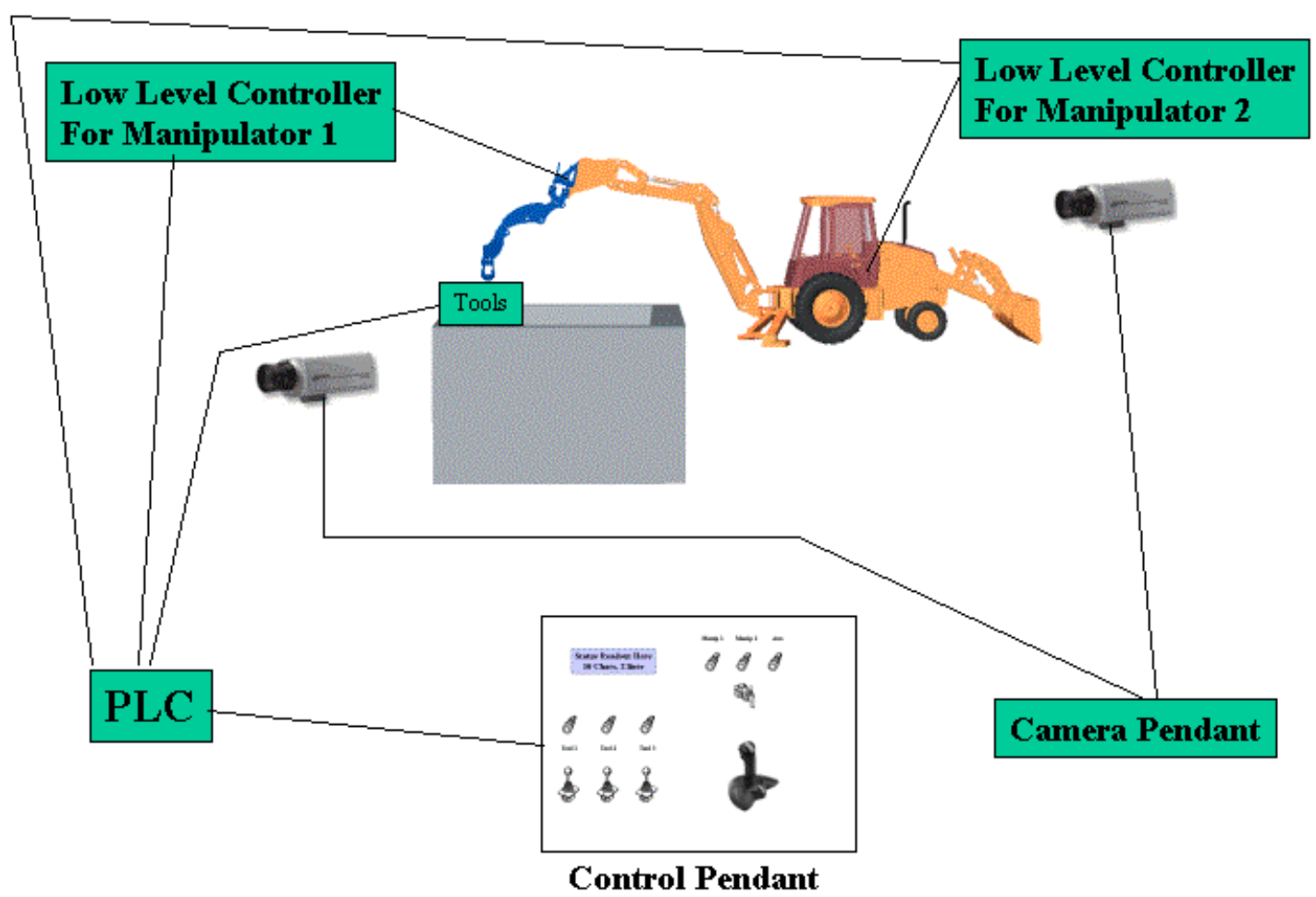

Figure 11.2. PLC-Based Control System

\subsection{Sensors}

Sensors will be required to provide safety and efficiency in performing some of the tasks.

1. Force/Torque Sensors. A force torque $(\mathrm{F} / \mathrm{T})$ sensor may be required for some tasks that require assembly or other interaction with the environment. A F/T sensor would be installed at the last link of the robot, and relay information back to the operator about the direction and magnitude of the forces at the end of the robot. This is valuable information when positioning a PUREX connector, or even cutting, to ensure not breaking the cutting blade by exerting a force perpendicular to the cutting blade. The F/T sensor can either be used passively, to adjust operator input according to the force applied, or actively, by relaying that information to a force reflecting master, which allows the operators to feel the forces. Unfortunately, force-reflecting master controllers are relatively expensive at this time, but they may be worth the cost for this system.

2. Collision Detection Sensors. There are a number of ways to detect collisions, which may or may not be necessary. One option that has been under development for awhile is a proximity sensor system that is applied to all the outside surfaces of the manipulator. However, this device is still under development, and may not be reliable in an industrial setting. The second option is to use pressure sensors within the manipulator to sense when an actuator is providing more force than should be necessary. This detects a collision after it happens, so if this method is used, the manipulator should be restricted in speed to prevent damage during a collision. A third method of collision detection 
involves a 3-D map of the pit and robot. This method relies heavily on the accuracy of the 3-D model, and could provide a false sense of security when there is no good information on the pit geometry. Also, the 3-D model solution is very costly, because of the computing power required, and the labor to build the computer model to be used, which would be different for each pit. 


\subsection{Final Concept Selection}

In meetings with the TFA, and NHC, each of the five potential concepts was presented and evaluated by the user (NHC). A gantry-based system with a 6-DOF manipulator was chosen as the preferred concept using the standard controls provided by the manufacturer. After deployment and successful operation, the system controls would be upgraded to a PLC-based control system. 


\section{Appendix A}

Pit Dimensional Data, and First and Second Cut Rankings 
Table A.1. Pit Identification and Dimensional Data

\begin{tabular}{|c|c|c|c|c|c|}
\hline \multicolumn{6}{|c|}{ INFORMATION ON TANK FARM PITS (dimensions in feet) } \\
\hline Location & Pump Pit & Sluce Pit & Valve Pit & Diversion Box & Other \\
\hline 241-A-SSTs & $6 \times 6 \times 9$ & $6 \times 6 \times 8.7$ & & & $\begin{array}{l}\text { Distribution Pit } 6 \times 5.5 \times 7 \\
\text { Receiving Pit } 6 \times 6 \times 9\end{array}$ \\
\hline 241-A-350 Drainage lift station & $9 \times 9 \times 11$ & & & & \\
\hline 241-A-417 Condensate catch tank & $16 \times 8 \times 14.5$ & & $5.3 \times 8 \times 14.5$ & & \\
\hline 241-A-A \& B Valve pits & & & $12 \times 10 \times 4.7$ & & \\
\hline 241-AX-SSTs & $8 \times 6 \times 9.4$ & $8 \times 6 \times 9$ & & & \\
\hline 241-AX-155 Diversion box & & & & $19 \times 6 \times 12$ & \\
\hline 241-AX-501 Valve pit & & & $2.7 \times 5.3 \times 6$ & & \\
\hline 241-AX-A \& B Valve pits & & & $10 \times 12 \times 1.5$ & & \\
\hline 241-A Lift station (DCRT) & $15 \times 13 \times 10$ & & & & Filter Pit $11 \times 11 \times 5.5$ \\
\hline 241-B-SSTs & $14 \times 17.5 \times 7$ & $9 \times 10 \times 7.5$ & & & \\
\hline 241-BX-SSTs & $14 \times 17.5 \times 8$ & $9 \times 10 \times 7.5$ & & & \\
\hline 241-BY-SSTs & $14 \times 17.5 \times 9$ & $9 \times 10 \times 7.7$ & & & \\
\hline 241-BX Saltwell system & $17 \times 19 \times 11.5$ & & & & \\
\hline 241-C-SSTs & $11 \times 14.7 \times 10.6$ & $8.5 \times 9 \times 4.7$ & & & Heel Pit 6x9x4.7 \\
\hline 241-S-SSTs & $7.5 \times 7.5 \times ?$ & $8 \times 14 x ?$ & $14 \times 8 \times 5.7$ & & \\
\hline 241-S-151 Diversion box & & & & $56 \times 24 \times 17$ & \\
\hline 241-SX-SSTs & $12.3 \times 7 \times 9.3$ & & $14 \times 8 \times 5.7$ & & \\
\hline \multicolumn{6}{|l|}{ 241-T-SSTs } \\
\hline 241-TX-SSTs & $7.1 \times 4.5 \times 4.3$ & $7.2 \times 5.7 \times 4.5$ & & & \\
\hline 241-TX-152 Diversion box & & & & $10.5 \times 8 \times 12$ & \\
\hline 241-TX-154 Diversion box & & & & $36 \times 10 \times 18$ & \\
\hline 241-TX-Catch tank (DCRT) & $17 \times 19 \times 16$ & & & & Filter Pit $11 \times 17 \times 16$ \\
\hline \multicolumn{6}{|l|}{ 241-TY-SSTs } \\
\hline 241-U-SSTs & $\begin{array}{l}6 \times 6 \times 4.5 \\
11 \times 14.5 \times 8\end{array}$ & $8.5 \times 9 \times 9$ & & & $\begin{array}{l}\text { Distribution Pit } 6.5 \times 6.5 \times 4.5 \\
\text { Cond. Pit } 8 \times 15 \times 7 \\
\text { Heel Pit } 6 \times 9 \times 4.5\end{array}$ \\
\hline
\end{tabular}


Table A.1. (contd)

\begin{tabular}{|c|c|c|c|c|c|}
\hline Location & Pump Pit & Sluce Pit & Valve Pit & Diversion Box & Other \\
\hline 241-U-151 Diversion box & & & & 20x9x16 & \\
\hline 241-U-152 Diversion box & & & & $28 \times 9 \times 17$ & \\
\hline 241-U-154 Diversion box & & & & $48 \times 10 \times 17$ & \\
\hline 241-U-Catch tank (DCRT) & $17 \times 19 \times 10$ & & & & Filter Pit 11x17x10 \\
\hline 241-A-151 Diversion box & & & & $54 \times 7.5 \times 10$ & \\
\hline 241-ER-151 Diversion box & & & & $7 \times 5 \times 10$ & \\
\hline 241-ER-152 Diversion box & & & & $43 \times 10 \times 17$ & \\
\hline 241-ER-153 Diversion box & & & & $12 \times 12 \times 15$ & \\
\hline 241-EW-151 Nozzle pit & & & & $15 \times 15 \times 12$ & \\
\hline 241-AN A \& B Pump pits & $14 \times 14 \times 6.7$ & & & $8 \times 6 \times 3.7$ & \\
\hline 241-AN-Process pits & 16x10x6 & & & & $\begin{array}{l}\text { Cond. Receiving Pit -02D } \\
8 \times 8 \times 11.6\end{array}$ \\
\hline 241-AP DSTs & $18 \times 12 \times 7.8$ & & & & $\begin{array}{l}\text { Ser. Pit } 12 \times 12 \times 3.5 \\
\text { Seal Pit } 9.8 \times 7 \times 9.3\end{array}$ \\
\hline 241-AW DSTs & $16 \times 10 \times 6$ & & $61 \times 16 \times 8$ & & \\
\hline 241-AY DSTs & $8 \times 12 \times 7.5$ & 6x8x9 & $14 \times 12 \times 6.6$ & & \\
\hline 241-AZ-101 \& 102 & $8 \times 12 \times 7.5$ & $6 \times 8 \times 9$ & $17.5 \times 7.3 \times 12.5$ & & \\
\hline \multicolumn{6}{|l|}{ 241-AZ-152 Diversion box } \\
\hline 241-AZ-152 Contamination storage box & $13 \times 13 \times 9$ & & $18 \times 11 \times 6.5$ & & \\
\hline 241-AZ-152 Catch tank & $6 \times 6 \times 14$ & & & & \\
\hline 241-AZ-154 Condensate & $5 \times 5 \times 7.5$ & & & & \\
\hline 241-SY DSTs & $16 \times 10 \times 7.6$ & & & & 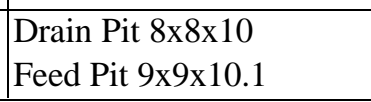 \\
\hline \multicolumn{6}{|c|}{$\begin{array}{l}\text { Pits not included in Table A.1 include: DST annulus pump pits and leak detection pits, Found SST pits, usually } 5 \text { feet in diameter, } \\
\text { made from corrugated culvert pipe. Many of the Table A.1 length and width dimensions are pit interior dimensions; therefore, } 3 \text { feet } \\
\text { must be added for the exterior dimension. Many of the depth dimensions are from the bottom of the pit to the top surface; however, } \\
\text { some are interior dimensions. } \\
\text { The information in Table A.1 came from many tank farm drawings and WHC-SD-WM-EV-040, Rev. 0, DST Ancillary Equipment } \\
\text { Evaluation, dated 9/7/90. }\end{array}$} \\
\hline
\end{tabular}


Table A.2. First and Second Cut Criteria and Rankings

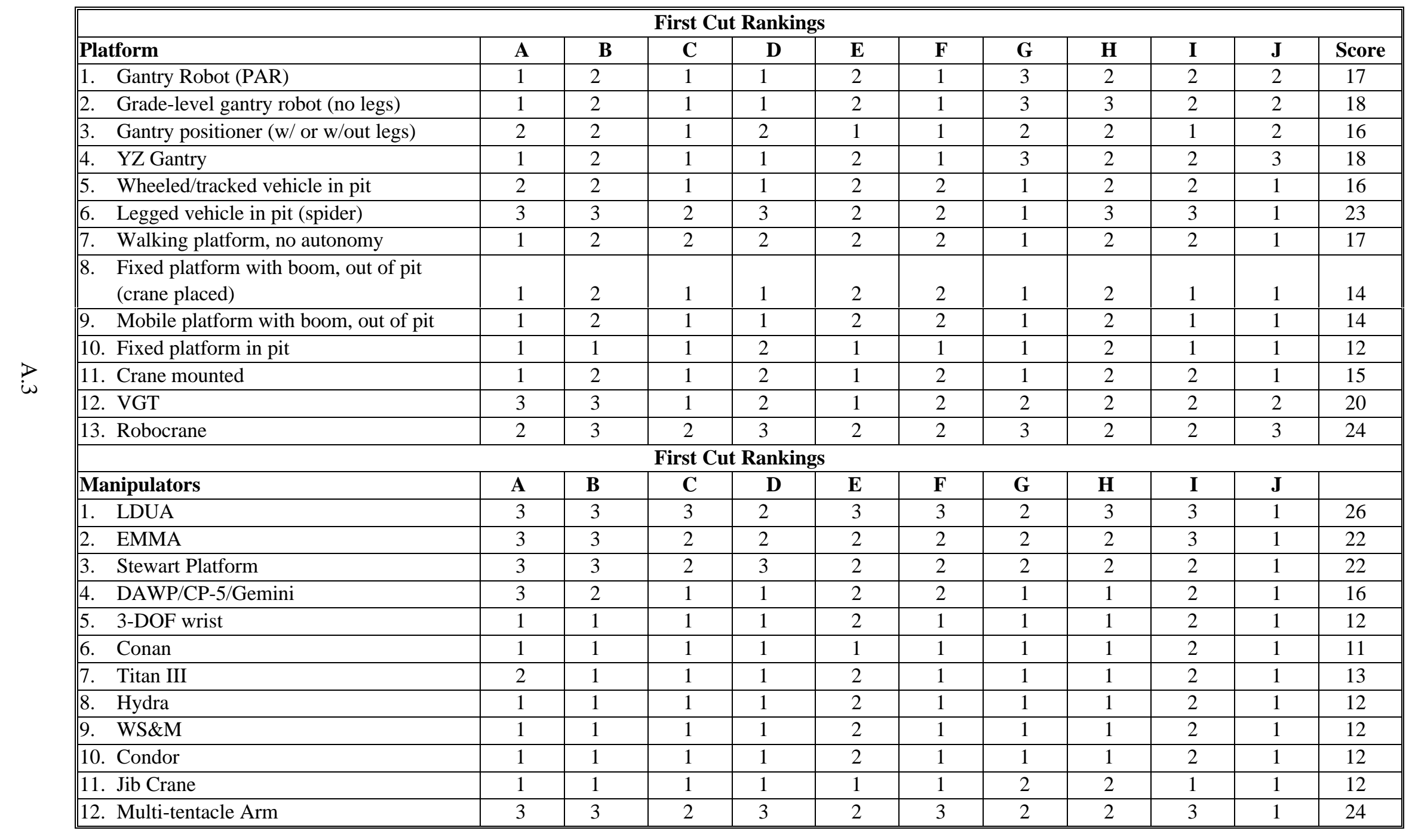


Table A.2. (contd)

\begin{tabular}{|c|c|c|c|}
\hline & \multicolumn{3}{|c|}{ Grade/Rank } \\
\hline First Cut Criteria & $\mathbf{1}$ & 2 & 3 \\
\hline A. Cost & $\$<300 \mathrm{~K}$ & $\$ 300-800 \mathrm{~K}$ & $\$ 900 \mathrm{~K}+$ \\
\hline B. Cold test by $9 / 00$ & $<6 \mathrm{mo}$. & 6-12 mo. & 12 mo. + \\
\hline C. Reliability & acceptable & unknown/doubtful & unacceptable \\
\hline D. Commercial availability & yes & engineering effort & development effort \\
\hline E. Maintainability & acceptable & unknown/doubtful & unacceptable \\
\hline Interaction with balance of system & plug \& play & some integ. effort & significant development effort \\
\hline G. Initial field setup & easy & moderate effort & substantial effort \\
\hline H. Acceptable to tank farm operations & fits in current ops & some changes & significant procedural changes \\
\hline I. Acceptable to equipment operators & familiar & somewhat unfamiliar & too technical \\
\hline J. $\quad$ Required support systems & none & some & lots \\
\hline
\end{tabular}


Table A.2. (contd)

Post First Cut Potential Systems

$\begin{array}{llll}\text { Platform Manipulators -> } & \text { DAWP } & \text { 3-DOF } & \text { 6-DOF } \\ \text { 1. Gantry Robot (PAR) } & \text { no } & \text { yes } & \text { yes } \\ \text { 2. Grade-level gantry robot (no legs) } & \text { no } & \text { yes } & \text { yes } \\ \text { 3. Gantry positioner (w/ or w/out legs) } & \text { no } & \text { no } & \text { yes } \\ \text { 4. YZ Gantry } & \text { no } & \text { no } & \text { yes } \\ \text { 5. Wheeled/tracked vehicle in pit } & \text { no } & \text { no } & \text { yes } \\ \text { 6. Walking platform, no autonomy } & \text { no } & \text { no } & \text { yes } \\ \text { 7. Fixed platform with boom, out of pit (crane placed) } & \text { no } & \text { yes } & \text { yes } \\ \text { 8. Mobile platform with boom, out of pit } & \text { no } & \text { yes } & \text { yes } \\ \text { 9. Fixed platform in pit } & \text { no } & \text { no } & \text { yes } \\ \text { 10. Crane mounted } & \text { no } & \text { no } & \text { yes } \\ \text { 11. Crane hook } & \text { yes } & \text { no } & \text { no }\end{array}$

\section{Summary of Possible Systems (15)}

Gantry robot with 3-DOF manipulator

Gantry robot with 6-DOF manipulator

Grade-level gantry robot (no legs) with 3-DOF manipulator

Grade-level gantry robot (no legs) with 6-DOF manipulator

Gantry positioner with 6-DOF

YX Gantry with 6-

DOF

Wheeled/tracked vehicle in pit with 6-DOF

Walking platform in pit with 6-DOF

Fixed platform with boom, with 3-DOF, out of pit (crane place)

Fixed platform with boom, with 6-DOF, out of pit (crane place)

Mobile platform with boom, with 3-DOF, out of pit

Mobile platform with boom, with 6-DOF, out of pit

Fixed platform in pit with 6-DOF

Crane mounted platform with 6-DOF

Crane deployed DAWP/Genisis 
Table A.2. (contd)

\section{System Capability Score for Completing Tasks}

\section{System}

Task \# ->

1. Gantry robot with 3-DOF manipulator

2. Gantry robot with 6-DOF manipulator

3. Grade-level gantry robot (no legs) with 3-DOF manipulator

4. Grade-level gantry robot (no legs) with 6-DOF manipulator

5. Gantry positioner with 6-DOF

6. YX Gantry with 6-DOF

7. Wheeled/tracked vehicle in pit with 6-DOF

8. Walking platform in pit with 6-DOF

9. Fixed platform with boom, with 3-DOF, out of pit (crane place)

10. Fixed platform with boom, with 6-DOF, out of pit (crane place)

11. Mobile platform with boom, with 3-DOF, out of pit

12. Mobile platform with boom, with 6-DOF, out of pit

13. Fixed platform in pit with 6-DOF

14. Crane mounted platform with 6-DOF

15. Crane deployed DAWP/Genisis

\begin{tabular}{ccccccc}
\multicolumn{2}{c}{ Rankings } & & & \multicolumn{2}{c}{ Score } \\
$\mathbf{1}$ & $\mathbf{2}$ & $\mathbf{3}$ & $\mathbf{4}$ & $\mathbf{5}$ & $\mathbf{6}$ & \\
1 & 2 & 2 & 1 & 1 & 2 & $\mathbf{9}$ \\
1 & 1 & 1 & 1 & 1 & 2 & $\mathbf{7}$ \\
2 & 2 & 2 & 1 & 2 & 2 & $\mathbf{1 1} *$ \\
1 & 1 & 1 & 1 & 1 & 2 & $\mathbf{7} *$ \\
1 & 1 & 1 & 1 & 1 & 2 & $\mathbf{7}$ \\
1 & 1 & 1 & 1 & 1 & 2 & $\mathbf{7}$ \\
3 & 2 & 2 & 2 & 1 & 2 & $\mathbf{1 2} *$ \\
3 & 2 & 2 & 2 & 1 & 2 & $\mathbf{1 2} *$ \\
1 & 2 & 2 & 1 & 2 & 1 & $\mathbf{9}$ \\
1 & 1 & 1 & 1 & 1 & 1 & $\mathbf{6}$ \\
1 & 2 & 2 & 1 & 2 & 1 & $\mathbf{9}$ \\
1 & 1 & 1 & 1 & 1 & 1 & $\mathbf{6}$ \\
3 & 2 & 3 & 2 & 1 & 2 & $\mathbf{1 3} *$ \\
2 & 1 & 1 & 1 & 2 & 1 & $\mathbf{8} *$ \\
1 & 1 & 2 & 1 & 1 & 1 & $\mathbf{7} *$
\end{tabular}

\section{Tasks to be Performed in Pits}

1. Jumper handling

2. Size reduction

3. Debris removal

4. Decontamination/fixative (spray only)

5. Tool holding (including brush or roller)

6. Jumper positioning

\section{Task Rating}

$1=$ Very Well

$2=\mathrm{OK}$

$3=$ Not Very Well

$*$ = Could require outside support equipment (jib crane to haul junk out of pit) 
Table A.2. (contd)

\section{Second Cut}

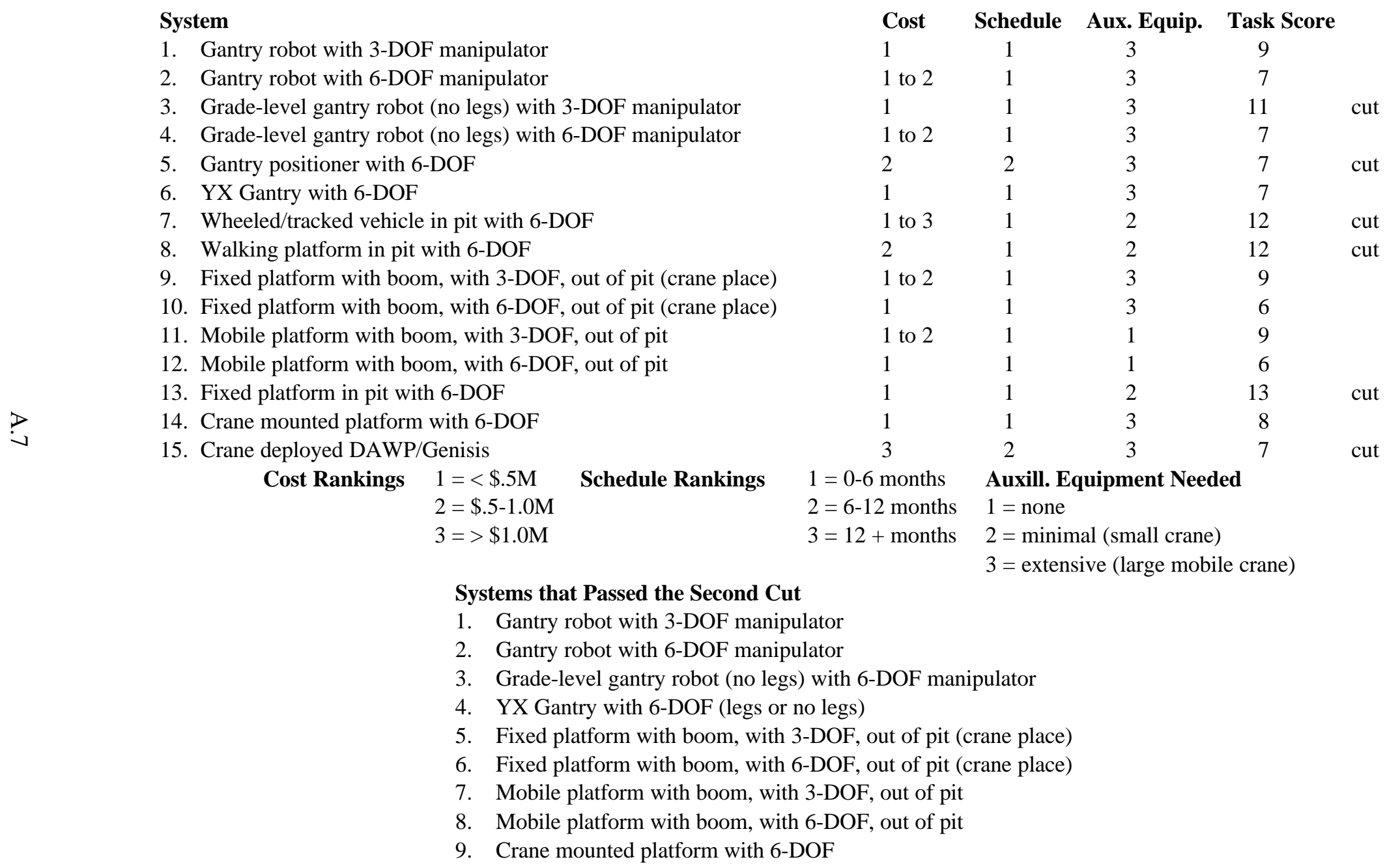




\section{Distribution}

No. of

Copies

\section{OFFSITE}

B. L. Burks

The Providence Group, Inc.

Fairview Technology Center

11020 Solway School Road, Suite 107

Knoxville, TN 37931

D. Haley

Oak Ridge National Laboratory

Bethel Valley Road, Building 7601

P.O. Box 2008

Oak Ridge, TN 37831-6304

R. Kress

Oak Ridge National Laboratory

Bethel Valley Road, Building 7601

P.O. Box 2008

Oak Ridge, TN 37831-6304

M. Noakes

Oak Ridge National Laboratory

Bethel Valley Road, Building 7601

P.O. Box 2008

Oak Ridge, TN 37831-6304
No. of

Copies

ONSITE

31 Pacific Northwest National Laboratory

J. M. Alzheimer

K5-22

S. A. Bailey (20)

K5-08

C. P. Baker

K5-22

J. T. Smalley

K5-26

J. C. Tucker

K5-22

Information Release Office (7)

Distr.1 